OPEN ACCESS

Edited by:

Esther Pueyo,

University of Zaragoza, Spain

Reviewed by:

Cees Korstanje,

Consultant, Nieuw-Vennep,

Netherlands

Thomas Seidel,

University of Erlangen Nuremberg,

Germany

Pei-Chi Yang,

University of California, Davis,

United States

*Correspondence:

István Baczkó

baczko.istvan@med.u-szeged.hu

Katja E. Odening

katja.odening@uniklinik-freiburg.de;

Katja.odening@pyl.unibe.ch

${ }^{+}$These authors have contributed equally to this work

Specialty section:

This article was submitted to

Cardiovascular and Smooth

Muscle Pharmacology,

a section of the journal

Frontiers in Pharmacology

Received: 31 October 2019

Accepted: 22 May 2020

Published: 05 June 2020

Citation:

Baczkó I, Hornyik T, Brunner M, Koren $\mathrm{G}$ and Odening KE (2020)

Transgenic Rabbit Models in Proarrhythmia Research.

Front. Pharmacol. 11:853. doi: 10.3389/fphar.2020.00853

\section{Transgenic Rabbit Models in Proarrhythmia Research}

\author{
István Baczkó $^{1 \star}$, Tibor Hornyik ${ }^{1,2,3 \dagger}$, Michael Brunner ${ }^{2,3,4}$, Gideon Koren ${ }^{5}$ \\ and Katja E. Odening ${ }^{2,3,6,7 *}$
}

1 Department of Pharmacology and Pharmacotherapy, University of Szeged, Szeged, Hungary, 2 Department of Cardiology and Angiology I, Heart Center, University of Freiburg, Freiburg, Germany, ${ }^{3}$ Faculty of Medicine, University of Freiburg, Freiburg, Germany, ${ }^{4}$ Department of Cardiology and Medical Intensive Care, St. Josefskrankenhaus, Freiburg, Germany, ${ }^{5}$ Cardiovascular Research Center, Division of Cardiology, Rhode Island Hospital, Alpert Medical School of Brown University, Providence, RI, United States, ${ }^{6}$ Translational Cardiology, Department of Cardiology, Inselspital, Bern University Hospital, Bern, Switzerland, 7 Institute of Physiology, University of Bern, Bern, Switzerland

Drug-induced proarrhythmia constitutes a potentially lethal side effect of various drugs. Most often, this proarrhythmia is mechanistically linked to the drug's potential to interact with repolarizing cardiac ion channels causing a prolongation of the QT interval in the ECG. Despite sophisticated screening approaches during drug development, reliable prediction of proarrhythmia remains very challenging. Although drug-induced long-QT-related proarrhythmia is often favored by conditions or diseases that impair the individual's repolarization reserve, most cellular, tissue, and whole animal model systems used for drug safety screening are based on normal, healthy models. In recent years, several transgenic rabbit models for different types of long QT syndromes (LQTS) with differences in the extent of impairment in repolarization reserve have been generated. These might be useful for screening/prediction of a drug's potential for long-QT-related proarrhythmia, particularly as different repolarizing cardiac ion channels are impaired in the different models. In this review, we summarize the electrophysiological characteristics of the available transgenic LQTS rabbit models, and the pharmacological proof-of-principle studies that have been performed with these models - highlighting the advantages and disadvantages of LQTS models for proarrhythmia research. In the end, we give an outlook on potential future directions and novel models.

Keywords: transgenic LQTS rabbit, drug-induced proarrhythmia, proarrhythmia safety screening, $\mathrm{K}^{+}$-channel blocker, long QT syndrome, cardiac repolarization reserve

\section{INTRODUCTION: PROARRHYTHMIA AND DRUG DEVELOPMENT}

Proarrhythmia - the triggering of arrhythmias following drug therapy-has been known for many decades as being caused by "anti"-arrhythmic cardiac drugs (Selzer and Wray, 1964; Echt et al., 1991; Waldo et al., 1996). This rare but lethal side-effect of drug therapy, however, is not restricted to anti-arrhythmic drugs, but occurs with a variety of other, non-cardiac drugs (Woosley et al., 1993; Wysowski and Bacsanyi, 1996; Darpo, 2001), and therefore is a major concern for patients, physicians, and the pharmaceutical industry. It has been estimated that around $20-60 \%$ of novel chemical entities have the potential to modulate the function of cardiac ion channels and therefore, 
to disturb normal cardiac electrical function (Danker and Moller, 2014). Depending on the nature of the drug-induced effects on ion channels function, proarrhythmia can be associated with prolongation or shortening of the QT interval (long QT syndrome, LQTS or short QT syndrome, SQTS, respectively) and/or with conduction disturbances.

For most drugs, proarrhythmia is assumed to be based on prolongation of cardiac repolarization as a result of druginduced inhibition of cardiac potassium currents (mostly $I_{\mathrm{Kr}}$ current(s)/HERG-channels) (Redfern et al., 2003). This acquired LQTS predisposes to Torsades-de-Pointes (TdP) polymorphic ventricular tachycardia that could lead to ventricular fibrillation and sudden cardiac death (SCD) (Haverkamp et al., 2000; Redfern et al., 2003; Fenichel et al., 2004). Although no less than $2-3 \%$ of all marketed drugs have the potential to induce LQTS (Stansfeld et al., 2006), the (documented) incidence of potentially lethal drug-induced $\mathrm{TdP}$ is typically very low (1:10,000 for non-cardiovascular drugs) (Yap and Camm, 2003), and therefore very hard to predict reliably (Fenichel et al., 2004). In recent decades, TdP-induced SCD cases were associated with a wide range of commonly used drugs (antipsychotics, anti-depressants, antihistamines, and antibiotics) (Haverkamp et al., 2000; Redfern et al., 2003; Fenichel et al., 2004) and many of them (such as cisapride, astemizole, terfenadine, grepafloxacin) have been withdrawn from the market (Farkas and Nattel, 2010; Stockbridge et al., 2013; Ferdinandy et al., 2019).

As a response from the regulatory authorities, the International Council for Harmonisation of Technical Requirements for Pharmaceuticals for Human Use (ICH) guidelines [ICH-S7B, 2005 (Food and Drug Administration, 2005b); ICH-E14, 2005 (Food and Drug Administration, 2005a)] were proposed for rigorous safety testing to avoid similar unacceptable human fatalities (SCD) in association with pharmacological therapy of non-life-threatening pathologies. Unfortunately, no "gold"-standard proarrhythmia screening method exist. Therefore, current safety screening in industry rely on combined use of pre-clinical in vitro assessment of HERG function, action potential (AP) and in vivo ECG (QT) assays, in silico computational (Yang et al., 2016; Ortega et al., 2017; Li et al., 2019) risk prediction [integrated risk assessment (IRA) approach], and clinical ECG studies (Food and Drug Administration, 2005a; Food and Drug Administration, 2005b). Usually, different proarrhythmia markers and score systems [see Proarrhythmia ECG Markers for Temporal Instability of Repolarization (Used in In Vivo and In Vitro Models)] are employed to try to increase the predictive value of the overall assessment (Hondeghem et al., 2001; Hondeghem and Hoffmann, 2003; Redfern et al., 2003; Lawrence et al., 2005) with moderate to limited success (Park et al., 2018).

Drug-induced $I_{\mathrm{Kr}} / \mathrm{HERG}$ blockade used to be considered the most important factor responsible for proarrhythmia formation. Therefore, for a long time, safety tests largely focused on detection of HERG-blocking potential of test compounds. As a result, this approach led to elimination of potentially promising drug candidates from the developmental pipeline solely on the basis of their potential to block the HERG channel (Carlsson, 2001; Bouder, 2007; Pugsley et al., 2008). HERG blockade plays an inevitably important role in proarrhythmia formation (Yap and Camm, 2003; Hancox et al., 2008); though, HERG block on its own does not necessarily lead to proarrhythmia since simultaneous reduction in other ion currents-such as in $I_{\mathrm{Na}}$ or $I_{\mathrm{Ca}}$-that may have anti-arrhythmic effects could modify the overall proarrhythmic potential of the drug (Van Opstal et al., 2001; Belardinelli et al., 2003; Thomsen et al., 2004; Anderson, 2006). On the other hand, compounds without HERG-blocking characteristics may still have proarrhythmic side effect via the inhibition of repolarizing ion currents such as the slow delayed rectifier potassium current $I_{\mathrm{Ks}}$ or the inward rectifier potassium current $I_{\mathrm{K} 1}$ (Pugsley et al., 2008; Roden, 2008; Kannankeril et al., 2010; Pollard et al., 2010). Based on the above, pharmaceutical industry has started the Comprehensive in vitro Proarrhythmia Assay (CiPA) initiative to work with validated assays, and to fill gaps in the internal proarrhythmia assessment with the overall goal to comply with the ICH-S7B guidelines. This new approach consists of three main elements: 1) systematic measurement of the effect of drug candidates on multiple human cardiac ion currents $\left(I_{\mathrm{Kr}}, I_{\mathrm{Ks}}, I_{\mathrm{Na} \text {,peak }}, I_{\mathrm{Na}, \text { late }}, I_{\mathrm{K} 1}, I_{\mathrm{to}}, I_{\mathrm{Ca}, \mathrm{L}}\right)$ in heterologous expression systems (Kramer et al., 2013; Cavero and Holzgrefe, 2014; Colatsky et al., 2016), 2) in silico integration of these ion channel effects, and 3) evaluation of the drug effect on integrated biological systems such as on stem-cell-derived cardiomyocytes (Colatsky et al., 2016; Crumb et al., 2016; Huang et al., 2017). According to a recent survey on current industrial safety screening practice (Authier et al., 2017), 90\% of the pharmaceutical companies use cell lines expressing cardiac ion channels, $50-60 \%$ of them perform ion channel binding assays, cardiac AP recordings or use human induced pluripotent stem cell-derived cardiomyocytes, and only around one-third of them integrate their electrophysiological results into an in silico model in order to better predict the drug effect on AP shape and duration. The CiPA initiative is undoubtedly a promising approach; however, its overall implementation is not sufficient yet.

The other major challenge in proarrhythmia screening derives from the huge inter-individual differences in susceptibility to arrhythmia, which makes the overall risk stratification particularly difficult. Gender, sex hormones, $\mathrm{K}^{+}$ homeostasis, and-most importantly_certain diseases highly influence the cardiac "repolarization reserve", defined as the ability of cardiomyocytes to maintain sufficient repolarization despite repolarization-prolonging (mostly $\mathrm{K}^{+}$channel blocking) effects via compensatory increase of non-affected "reserve" outward $\mathrm{K}^{+}$currents (Roden, 1998; Varro and Baczko, 2011).

Apart from a decrease in serum $\mathrm{K}^{+}$concentration that results in a massive prolongation of cardiac repolarization, cardiovascular and metabolic diseases such as congestive heart failure (Kjekshus, 1990), cardiac hypertrophy, hypertrophic and dilated cardiomyopathy (Decker et al., 2009), ischemia (Dutta et al., 2016), congenital LQTS (El-Sherif and Turitto, 1999), or diabetes mellitus (Mcnally et al., 1999; Whitsel et al., 2005) play the most important role in decreasing repolarization reserve capacity and thereby in increasing susceptibility to proarrhythmia. 
Despite the fact that drug-induced TdP occur mostly in patients with reduced cardiac repolarization reserve, current safety assessments rely still mainly on tests performed on healthy animals with intact repolarization or on their tissues/ cells (Food and Drug Administration, 2005a; Food and Drug Administration, 2005b). Consequently, new animal models, (i) with increased sensitivity to channel blockers other than only HERG, such as $I_{\mathrm{Ks}}$ or $I_{\mathrm{K} 1}$, and (ii) representing different degrees of impairment in their cardiac repolarization reserve were suggested to employ in proarrhythmia research (Hornyik et al., 2020).

Sex hormones also can significantly alter the individual's repolarization reserve capacity and therefore affect susceptibility to arrhythmia. Women are at higher risk for drug-induced prolongation of repolarization and drug-induced TdP (Lehmann et al., 1996; Benton et al., 2000; Wolbrette, 2003; Gowda et al., 2004). This is due to sex hormone effects on cardiac ion currents/channels (Yang and Clancy, 2010; Odening and Koren, 2014): estrogen prolongs cardiac repolarization by decreasing $I_{\mathrm{Ks}}$ (Drici et al., 1996) and $I_{\mathrm{Kr}}$ (Kurokawa et al., 2008; Ando et al., 2011) and by increasing $I_{\mathrm{Ca}, \mathrm{L}}$ (Odening et al., 2012a; Odening et al., 2012b) and NCX expression (Chen et al., 2011); therefore, estrogen reduces repolarization reserve and favors drug-induced arrhythmia. In contrast, testosterone and progesterone both increase repolarization reserve by increasing $I_{\mathrm{Ks}}$ [testosterone (Liu et al., 2003)/progesterone (Furukawa and Kurokawa, 2008)], $I_{\mathrm{K} 1}$ and $I_{\mathrm{Kr}}$ (testosterone) (Liu et al., 2003), decreasing $I_{\mathrm{Ca}, \mathrm{L}}$ [testosterone (Furukawa and Kurokawa, 2008)/progesterone (Odening et al., 2012a; Odening et al., 2012b)], and upregulating SERCA expression [progesterone (Odening et al., 2012a; Odening et al., 2012b; Moshal et al., 2014)], thereby exerting a protective, "antiarrhythmic" effect against drug-induced proarrhythmia (Odening et al., 2012a; Odening et al., 2012b). These observations have consequences for proarrhythmia research, as female animal models (or animal models with altered hormonal state) might be particularly sensitive in detecting potential ion channel-blocking properties of drug candidates.

In this review, we first give an overview about currently employed proarrhythmia markers, the importance of the choice of species for proarrhythmia research, and the advantages and disadvantages of currently used in vivo proarrhythmia models, followed by a detailed description of novel transgenic LQTS rabbit models. Finally, we provide a brief outlook on possible future directions and novel models in the field.

\section{Proarrhythmia ECG Markers for Temporal Instability of Repolarization (Used in In Vivo and In Vitro Models)}

Based on the clinical observations that TdP mostly occurred in the setting of prolongation of ventricular repolarization/QT prolongation (Haverkamp et al., 2000; Redfern et al., 2003), preclinical and clinical safety tests have for a long time focused on QT prolongation as a surrogate marker for TdP risk (Food and Drug Administration, 2005b). However, it has been known for some time that prolongation of repolarization does not always equally increase pro-arrhythmic risk since numerous drugs that block $I_{\mathrm{Kr}} / \mathrm{HERG}$ and prolong QT rarely cause TdPwhile others causing less pronounced QT prolongation carry a significant pro-arrhythmic risk (Zhang et al., 1999; Yang et al., 2001; Roden, 2004; Thomsen et al., 2004; Shah and Hondeghem, 2005). Indeed, the extent of QT prolongation did not predict serious ventricular arrhythmias and/or SCD in different rabbit and dog experimental models (Amos et al., 2001; Thomsen et al., 2004; Shah and Hondeghem, 2005; Lengyel et al., 2007a; Jacobson et al., 2011) or in patients with (Strasberg et al., 1983; Yi et al., 1998; Maron et al., 2001; Hinterseer et al., 2009; Hinterseer et al., 2010) or without (Eisenberg et al., 1995; Kusano et al., 2001; Paltoo et al., 2001) congenital/structural heart disease. Thus, these safety tests can yield either false positive results, halting the development of a promising new drug (Roden, 2004; Hondeghem et al., 2007) or false negative results, causing harm to patients with increased susceptibility to arrhythmia. Therefore, there is an unmet need for (i) improved identification of patients at elevated risk for drug-induced arrhythmia (Kaab et al., 2003) and (ii) novel ECG markers with better predictive value for pro-arrhythmic drug adverse effects.

A number of different electrophysiological parameters have been investigated as non-invasive prognostic markers for TdP and SCD risk evaluation both in animal experiments and in the clinical setting. These novel markers mostly derive from the original work by Hondeghem et al., suggesting the assessment of AP triangulation, instability, and dispersion (Hondeghem et al., 2001). These markers were later supplemented by evaluation of disturbances in cardiac wavelength (Hondeghem et al., 2007; Hondeghem, 2016). The importance of an increased spatial (transmural, apico-basal, or inter-ventricular) dispersion of repolarization in reentry-based arrhythmia formation was further supported by other studies (Antzelevitch, 2008; Barbhaiya et al., 2013; Guerard et al., 2014). Therefore, $\mathrm{T}_{\text {peak- }}$ end - the length from the beginning of the $T$ wave $\left(T_{p}\right)$ to the end $\left(\mathrm{T}_{\mathrm{e}}\right)$ on ECG-that reflect the transmural dispersion of repolarization was suggested to use as an indicator of arrhythmic risk, although, no clear consensus about the value of this parameter has been reached so far (Antzelevitch, 2008; Barbhaiya et al., 2013; Meijborg et al., 2014). Of note, dispersion of repolarization was recently identified (experimentally and by computational modeling) as cause for triggered activity/EAD formation, further enhancing the need to assess dynamic dispersion of repolarization noninvasively (Liu et al., 2018).

The temporal instability of cardiac repolarization can be described by different variables characterizing the small beatto-beat fluctuations in the QT interval as QT variability [for a recent review see (Baumert et al., 2016)]. Beat-to-beat variability of repolarization can be quantified by calculating the short-term variability of the QT (STV ${ }_{\mathrm{QT}}$ ) (Thomsen et al., 2004). First in the chronic AV-block dog model, then in other animal experimental proarrhythmia models (Thomsen et al., 2004; Lengyel et al., 2007a; Jacobson et al., 2011) and in clinical settings (Hinterseer et al., 2008; Hinterseer et al., 2009; Hinterseer et al., 2010; Oosterhoff et al., 2010), it has been repeatedly shown that $\mathrm{STV}_{\mathrm{QT}}$ has a higher predictive value for proarrhythmia risk 
than the overall prolongation of repolarization (QT duration). $\mathrm{STV}_{\mathrm{QT}}$ has been used in several studies to confirm the safety of different drugs (Oros et al., 2006; Antoons et al., 2010; Varkevisser et al., 2012), to characterize pro-arrhythmic drug effects (Thomsen et al., 2004; Thomsen et al., 2006b; Kristof et al., 2012), and to assess temporal repolarization instability in patients with co-morbidities associated with repolarization disturbances (Orosz et al., 2015a; Orosz et al., 2015b; Orosz et al., 2017).

Based on the above, it is justified and required to assess and validate measures of temporal QT variability in animal experimental models of proarrhythmia.

\section{CURRENT IN VIVO MODELS FOR PRE- CLINICAL PROARRHYTHMIA SAFETY SCREENING AND THEIR LIMITATIONS}

\section{Choice of Models: Species Differences in Repolarizing Currents}

Cardiac electro-mechanical function shows large inter-species variability. These species differences are especially striking in regard to cardiac repolarization that is governed by tightly regulated activities of various inward and outward ion currents.

Small rodents like mice or rats are commonly used animals for studying ischemia-induced arrhythmias (which are often linked to conduction properties), since cardiac conduction properties in these animals are governed by $\mathrm{Na}^{+}$currents, $\mathrm{Ca}^{2+}$ currents, and connexin function that are very similar to those in human (Derangeon et al., 2012; Kaese and Verheule, 2012). Furthermore, they have the advantage of low cost, short lifecycle, and their genetic manipulation is much easier than that in larger animals (see Genetically Modified Mouse Models With Reduced Repolarization Reserve). On the other hand; however, they have limited value in studying (prolonged) repolarizationrelated arrhythmogenesis: in mice and rats the fast and slow transient outward $\left(I_{\mathrm{to}}\right)$, and the delayed rectifier $\left(I_{\mathrm{K} \text {,slow1 }}\right.$ and $I_{\mathrm{K}, \text { slow2 }}$ ) (Xu et al., 1999; Brunner et al., 2001; Liu et al., 2008) voltage-gated potassium currents play a major role in repolarization-while in dogs, rabbits, and humans the rapid and slow delayed rectifier potassium currents $\left(I_{\mathrm{Kr}}\right.$ and $\left.I_{\mathrm{Ks}}\right)$ are the major determinants of cardiac repolarization (Varro et al., 1993; Nerbonne, 2000; Nerbonne and Kass, 2005; Grandy et al., 2007; Saito et al., 2009; Yang et al., 2014). The exact role of $I_{\mathrm{Kr}}$ and $I_{\mathrm{Ks}}$ in small rodents is still not well known and controversial (Nerbonne and Kass, 2005; Grandy et al., 2007; Saito et al., 2009; Yang et al., 2014). As a result, the shape of their AP is different compared to larger animals and humans (triangular shape vs. rectangular AP with prominent plateau phase) (Nerbonne and Kass, 2005; Grandy et al., 2007; Saito et al., 2009; Yang et al., 2014), as well as their pharmacological responses to proarrhythmic potassium channel blocking drugs (Figures 1A, B).

Acute $I_{\mathrm{Kr}}$-blocker administration, for example, prolongs repolarization in dogs, rabbits, and humans but not in mice or

A

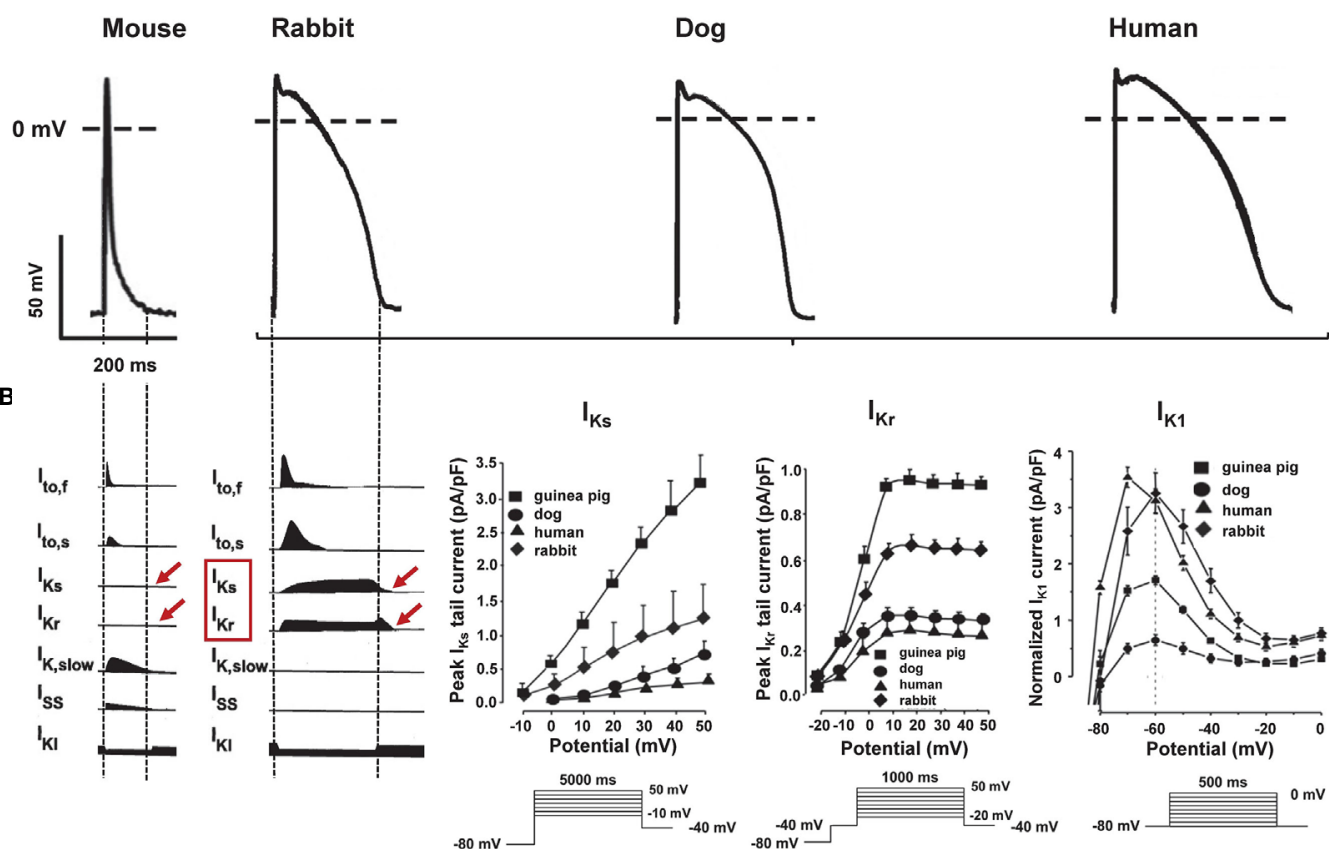

FIGURE 1 | Species differences in repolarizing ion currents. (A) Representative action potential (AP) recordings [modified from (Rudy et al., 2008; Blenck et al., 2016)] and (B) schematic illustration of the main repolarizing ion currents in mouse, rabbit, dog, and human cardiomyocytes [modified from (Nerbonne et al., 2001)]. Panel (C) shows species differences in $I_{K_{s}}, I_{K r}$, and $I_{K 1}$ in rabbit, dog, and human. 
rats (Varro et al., 2000; Nagy et al., 2009; Jost et al., 2013; Yang et al., 2014). Chronic administration of the $I_{\mathrm{Kr}}$-blocker dofetilide that prolongs repolarization in larger animals and human subjects by blocking HERG channels on the other hand, lengthen repolarization in mice-at least partly-by increasing $I_{\mathrm{Na}, \mathrm{L}}$ (via phosphoinositide 3-kinase pathway) (Yang et al., 2014). Based on the above, mice and rats have serious limitations in drug-induced proarrhythmia research with little translational potential.

In contrast, the function and gating kinetics of various cardiac potassium channels are very similar in dogs, rabbits, and humans with $I_{\mathrm{Kr}}$ and $I_{\mathrm{Ks}}$ as main repolarizing ion currents in all three species (Varro et al., 1993; Nerbonne, 2000; Nerbonne and Kass, 2005; Jost et al., 2013), with slight inter-species differences: In humans and dogs-just as in most mammals $-I_{\text {to }}$ is formed of two distinct subtypes named as $I_{\text {to,fast }}$ and $I_{\text {to,slow }}$-with fast and slow recovery from inactivation, determined by Kv3.4 and Kv1.4, respectively (Patel and Campbell, 2005) as opposed to rabbits, where $I_{\text {to,slow }}$ is the primary transient $\mathrm{Kv}$ current in the left ventricle (Fedida and Giles, 1991), while in the right ventricle $I_{\text {to, }}$ fast and its role in LQT1 related arrhythmogenesis has recently been confirmed (Choi et al., 2018). The repolarization capacity of rabbits and dogs is more robust than that in humans due to higher $I_{\mathrm{K} 1}, I_{\mathrm{Kr}}$, and $I_{\mathrm{Ks}}$ current densities (Jost et al., 2013; Husti et al., 2015) (Figure 1C).

In summary, the rabbit has a prominent role in arrhythmia research, since: (i) the shape of AP (Varro et al., 1993) and the function and gating kinetics of the underlying cardiac ion channels/currents (Nerbonne, 2000), (ii) the myocardial mechanical function (Jung et al., 2012), (iii) the relative effective heart size relating cardiac mass to the frequency of VF (Panfilov, 2006), and (iv) their responses to pharmacological interventions (Harken et al., 1981) show very close resemblance to human cardiac physiology. Based on the above-described species differences in various ion currents, the rabbit could have advantages over dog models when testing the proarrhythmic potential of drugs with $I_{\mathrm{Kr}}, I_{\mathrm{Ks}}$, or $I_{\mathrm{K} 1}$-blocking properties since they show very good similarity to human physiology in these currents and are cheaper, easier to handle, and to breed than dogs and can be modified genetically. Dogs or guinea pigs, on the other hand, may be better suited to use for studying arrhythmogenesis in which $I_{\text {to }}$-inhibition plays an important role.

\section{In Vivo Proarrhythmia Models With Reduced Repolarization Reserve}

Both drug-induced and genetically modified animal models with impaired repolarization reserve have been generated in various species (such as dogs, mice, and rabbits) and utilized to investigate drug-induced proarrhythmia and its underlying mechanisms [reviewed in (Salama and London, 2007; Lang et al., 2016)]. In addition, animal models with cardiac diseases -e.g. chronic heart failure, hypertrophic cardiomyopathy, diabetes mellitus etc.-leading to electrical remodelingassociated alterations of repolarization reserve can be used for proarrhythmia research. These models have the advantage that they mimic some of the diseases that also predispose human patients to drug-induced arrhythmias.

One main shortcoming of drug-induced animal models, however, is the fact that drugs have to be administered continuously to sustain the drug-induced reduction of repolarization reserve, thus impeding detailed investigation of (long-term) proarrhythmia in free-moving, non-anesthetized animals.

One main short-coming of genetically modified mouse models - the only genetic models with reduced repolarization reserve available until 2008-are the pronounced species differences in cardiac electrophysiology with different ion currents conveying cardiac repolarization in human and murine cardiomyocytes (Varro et al., 1993; Nerbonne, 2000; Nerbonne and Kass, 2005; Jost et al., 2013) as highlighted in the subchapter above.

High cost and need for special technical expertise for example are considered as main shortcomings for the generation of disease-related animal models with cardiac electrical remodeling.

\section{Drug-Induced Animal Models With Reduced Repolarization Reserve}

One frequently used drug-induced model is the methoxaminesensitized rabbit model: anesthetized rabbits are sensitized with the selective $\alpha$-adrenoceptor-agonist methoxamine, which makes them particularly prone to develop drug-induced ventricular tachycardia when exposed to HERG $/ I_{\mathrm{Kr}}$-blocking drugs (Carlsson, 2008; Carlsson et al., 2009). The choice of the anesthetic regimen, however, strongly influences the extent of proarrhythmia development in this model-as the different anesthetics all have different intrinsic cardiac ion channelblocking properties (Carlsson, 2008; Inaba et al., 2011), indicating the importance of the degree of ion channel blockade in these "mixed" drug-induced models. Pro- and anti-arrhythmic properties of various different drugs have been tested and classified as having a low, intermediate, or high proarrhythmic potential for drug-induced TdP using this model (Diness et al., 2008; Carlsson et al., 2009; Jacobson et al., 2011; Mow et al., 2015; Varkevisser et al., 2015). However, as the model depends on $\alpha$-adrenoceptor sensitization, the full extent of proarrhythmic potential of drugs that concomitantly block $I_{\mathrm{Kr}}$ and $\alpha$-adrenoceptors (such as quinidine, cisapride, quinolone) may not be fully appreciated by this model (Carlsson, 2008; Mow et al., 2015).

Other frequently employed drug-induced rabbit models are based on the ex vivo blockade of HERG/I $/ I_{\mathrm{Kr}}$ by E-4031 (Choi et al., 2002; Maruyama et al., 2011; Parikh et al., 2012; Lau et al., 2015) or by dofetilide (Farkas et al., 2006; Dhein et al., 2008; Orosz et al., 2014), thus generating a drug-induced rabbit model representing LQT2 characteristics. Similar to the genetic reduction of $I_{\mathrm{Kr}}$ in congenital LQT2, the drug-blockade of $I_{\mathrm{Kr}}$ by E-4031 or dofetilide leads to a high propensity for arrhythmia development in ex vivo Langendorff-perfused rabbit heartsparticularly when perfused with low $\mathrm{K}^{+}$and $\mathrm{Mg}^{2+}$ solutions (Maruyama et al., 2011; Milberg et al., 2011). Similarly, QTc prolongation and arrhythmia susceptibility is particularly high 
A Parallel block of $I_{K s}$ and $I_{K r}$ increases TdP incidence in rabbits QTc interval

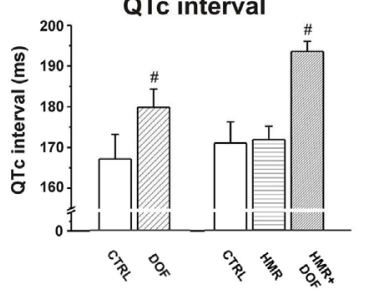
Incidence of TdP

B

Downregulation of $\mathrm{I}_{\mathrm{Ks}}$ and $\mathrm{I}_{\mathrm{Kr}}$ in dogs with chronic AV-block
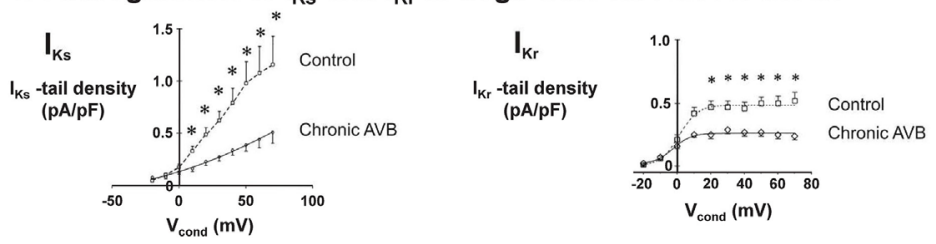

C D-Sotalol induces TdP in dogs with chronic AV-block
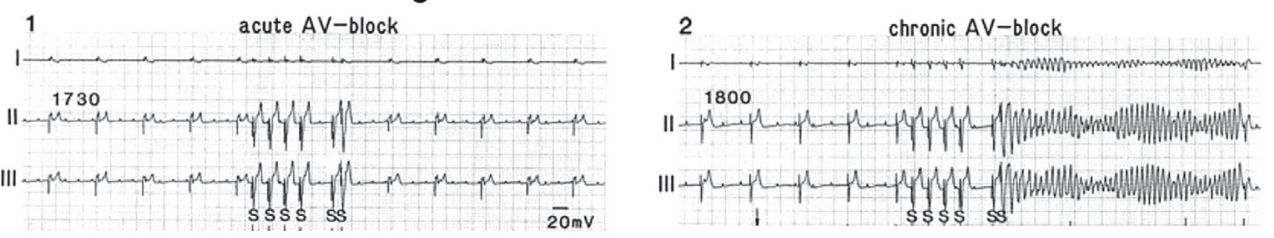

FIGURE 2 | Pro-arrhythmia detection with acquired LQT rabbit and chronic AV-block dog models. (A) Left panel: The QTc interval was significantly prolonged by the $I_{k r}$ blocker dofetilide and was further prolonged by the combination of dofetilide and the $I_{k r}$ blocker HMR1556 given in any order, while $I_{k s}$ block alone did not prolong the QTc in anesthetized rabbits. Right panel: $I_{\mathrm{Kr}}$ block caused TdP in some of the animals, $\mathrm{I}_{\mathrm{ks}}$ block alone did not induce TdP in anesthetized rabbits. Importantly, combined acute pharmacological block of $\mathrm{I}_{\mathrm{Ks}}$ and $\mathrm{I}_{\mathrm{Kr}}$, given in any order, caused a significant increase in TdP incidence. \#p $<0.05 \mathrm{vs}$. baseline control in the same group; ${ }^{*} \mathrm{p}$ < 0.05 vs. dofetilide. N=7-11 animals/group. CTRL: Control, DOF: Dofetilide, HMR: HMR-1556. Modified from (Lengyel et al., 2007a). (B) In right ventricular cardiomyocytes isolated from dogs with chronic AV-block and marked myocardial hypertrophy, $\mathrm{I}_{\mathrm{Ks}}$ tail current density was reduced by approximately $55 \%$ $(n=9)$, while $I_{k r}$ tail current density was reduced by $45 \%(n=14)$ compared to those isolated from control animals. * $p<0.05$ vs. control myocytes. Modified from (Nolders et al., 1999). (C) Standard bipolar ECG lead recordings illustrating a marked difference in the arrhythmogenic response to administration of the selective $\mathrm{I}_{\mathrm{Kr}}$ blocker D-sotalol in dogs with acute (left panel) and chronic AV-block (right panel). The pacing protocol involved a basic pacing cycle length (CL) of $1730 \mathrm{~ms}$ in acute AV block, and 1800 ms spontaneous idioventricular CL in chronic AV-block. Arrhythmia provocation included a short/long/short sequence at 600 ms CL for 4 beats followed by 2 paced beats with 1200 and 350 ms cycle lengths. No TdP was observed in acute AV-block dogs, while 60\% of animals with chronic AV-block exhibited TdP. Modified from (Nos et al., 1998).

when HERG/ $I_{\mathrm{Kr}}$ blockade is combined with $\mathrm{KvLQT} 1 / I_{\mathrm{Ks}}$ blockade by HMR-1556 (Lengyel et al., 2007a) (Figure 2A).

\section{Genetically Modified Mouse Models With Reduced Repolarization Reserve}

Despite apparent differences between human and mouse electrophysiology-e.g., different ion currents conveying cardiac repolarization in human and murine cardiomyocytes, a different shape of the AP, and a magnitude-faster heart rate in mice [reviewed in (Nerbonne, 2000); (Salama and London, 2007); (Baczko et al., 2016)], the first transgenic and knock-out animal models of LQTS were mouse models (London et al., 1998). The reason for this was that genetic manipulation has for a long time nearly exclusively been feasible in mice and not in other larger mammals such as rabbits. Transgenic models based on mutations in human potassium channel genes or knock-out/knock-in models of mouse potassium channel genes could only partially mimic the characteristics of human patients with impaired repolarization reserve [reviewed in detail in (Nerbonne et al., 2001); (Lang et al., 2016); (Ziupa et al., 2019)], while genetically modified mouse models with mutations in the sodium channel gene (SCN5A; LQT3) more closely mimic the human long QT disease phenotype with AP duration (APD) and QT prolongation as well as spontaneous life-threatening ventricular arrhythmia (Nuyens et al., 2001; Fabritz et al., 2003), since SCN5A drives the majority of depolarizing $\mathrm{Na}^{+}$currents in both human and murine cardiomyocytes (Derangeon et al., 2012).

None of these mouse models, however, have been systematically used for proarrhythmia research-mainly due to the fact that $I_{\mathrm{Kr}}$ current (the most frequent target for drugs inducing proarrhythmia) plays no major role in cardiac repolarization in mice.

\section{Animal Models With Structural/Electrical Remodeling and Reduced Repolarization Reserve}

Several experimental animal models of different species exist that are characterized by impaired repolarization reserve associated with cardiac structural and/or electrical remodeling. The most thoroughly characterized of these is the canine cardiac volume 
overload model with chronic atrioventricular block (Vos et al., 1995). Three months following AV-node ablation, these dogs exhibit severe bradycardia and eccentric, biventricular myocardial hypertrophy without heart failure (Vos et al., 1998). Importantly, the model is characterized by heterogeneous prolongation of APD at baseline and further APD-prolongation and early afterdepolarization (EAD) development upon administration of $I_{\mathrm{Kr}}$-blocker $d$-sotalol, indicating increased susceptibility to druginduced TdP (Vos et al., 1998) (Figure 2C). A significant downregulation of potassium currents, including $I_{\mathrm{Ks}}$ - a key player in ventricular repolarization reserve in mammals including humans (Varro et al., 2000; Volders et al., 2003; Jost et al., 2005)—was observed in both left and right ventricular cardiomyocytes isolated from dogs with chronic AV block (Volders et al., 1999) (Figure 2B). In addition, $I_{\mathrm{Kr}}$ density was reduced by $45 \%$ in right ventricular myocytes, while left ventricular (LV) $I_{\mathrm{Kr}}$ density was unchanged (Volders et al., 1999).

The ability of the model to detect drug-induced TdP was validated (Takahara et al., 2006) with several drugs such as the $\mathrm{H}_{1}$ antihistamine terfenadine (Monahan et al., 1990), the antipsychotic drug sertindole (Thomsen et al., 2003), and the $\mathrm{D}_{2}$ dopamine receptor antagonist sulpiride (Sugiyama et al., 2002). Moreover, with this model, it was demonstrated for the antibiotics moxifloxacin and azithromycin that QT prolongation does not necessarily cause TdP (Thomsen et al., 2006a). An important advantage of this model is an improved proarrhythmia reproducibility within the same experimental animal (Verduyn et al., 2001). There are, however, some disadvantages that may prevent this model from becoming widely used for proarrhythmia research: it is a relatively expensive, time consuming (at least 3 months have to pass before ventricular hypertrophy and increased susceptibility to arrhythmia develops) and low throughput method that requires special technical expertise for performing AV-node ablation (Vos et al., 1998).

In diabetes, a moderate remodeling-associated QT prolongation has been shown (Giunti et al., 2007), and diabetes has been associated with increased risk of SCD (Gill et al., 2009), indicating the patients' higher susceptibility to proarrhythmia. Similarly, in rabbit and dog models of diabetes mellitus, a mild prolongation of repolarization and a decreased repolarization reserve due to downregulation of $I_{\mathrm{Ks}}$ and $I_{\text {to }}$ (reversible by insulin treatment) were observed (Lengyel et al., 2007b; Lengyel et al., 2008). The authors are not aware, however, of any published studies using experimental diabetes animal models in species with repolarization relevant to human (i.e. not mice or rats) for testing pro-arrhythmic effects of drugs in this "patient" cohort.

\section{TRANSGENIC LQTS RABBIT MODELS WITH IMPAIRED REPOLARIZATION RESERVE (LQTS)}

Since cardiac electrophysiological characteristics of the rabbit is much closer to humans than that of mice or rats (Varro et al.,
1993; Nerbonne, 2000; Nerbonne and Kass, 2005; Jost et al., 2013), - similar potassium currents (mainly $\mathrm{I}_{\mathrm{Kr}}$ and $\mathrm{I}_{\mathrm{Ks}}$ ) convey the cardiac repolarization in rabbits and humans-transgenic LQTS rabbit models were generated as soon as it became technically feasible (Bosze et al., 2016) to better mimic pathophysiology of (human) LQTS patients with decreased repolarization reserve, who are most vulnerable to the development of drug-induced arrhythmias.

\section{Generation of Transgenic LQTS Rabbit Models}

To generate transgenic LQTS rabbit models with impaired repolarization reserve, the so-called "dominant-negative" transgenic strategy, which describes the fact that the co-assembly of mutated and normal channel subunits completely disrupts the overall ion channel function, was utilized to decrease the expression of functionally normal repolarizing potassium channel proteins. All available transgenic LQTS rabbit models have been engineered by beta-myosin heavy chain promoter-driven cardio-selective overexpression of mutated human genes encoding for voltage-gated $\mathrm{K}^{+}$ channels such as KCNQ1/KvLQT1 (KvLQT1-Y315S, LQT1), KCNH2/HERG (HERG-G628S, LQT2), or KCNE1/minK (KCNE1-G52R) (Brunner et al., 2008; Major et al., 2016).

To generate the transgenic founder animals, the pronuclear microinjection technique was used. Superovulation was induced in wild-type (WT) rabbits using hormonal stimulation with FSH and GnRH-analogues, and inseminated oocytes were microinjected with transgenic mutant DNA-constructs and reimplanted into foster mothers (Brunner et al., 2008; Major et al., 2016). Mating of the resulting transgenic F0 founders with female WT rabbits resulted in vertical transmission with $50 \%$ transgenic and 50\% WT offspring. To generate doubletransgenic LQT2-5 rabbits, LQT2 male and LQT5 female rabbits were cross-bred (Hornyik et al., 2020).

\section{Electrophysiological Characteristics and Arrhythmogenic Mechanisms in the Transgenic LQTS Models}

In LQT1 or LQT2 rabbit cardiomyocytes the repolarizing potassium currents $I_{\mathrm{Ks}}$ (LQT1) or $I_{\mathrm{Kr}}$ (LQT2), respectively, are completely eliminated. This results in a prolongation of APD on the cellular and whole heart levels and a prolongation of ventricular refractoriness and QT interval duration in vivo (Brunner et al., 2008; Odening et al., 2010). This prolongation of $\mathrm{APD} / \mathrm{QT}$ is particularly pronounced at slower heart rates, leading to a steeper QT/RR ratio-particularly in LQT2 (Brunner et al., 2008) (Figures 3A-C). Moreover, these models demonstrate an increased temporal instability of QT duration with an increased STV $\mathrm{QT}_{\mathrm{QT}}$ (Hornyik et al., 2020) and spontaneous polymorphic VT in LQT2 [158] (Figure 3D).

In transgenic LQT5 rabbit cardiomyocytes, in contrast, the biophysical properties of $I_{K s}$ and $I_{K r}$ are altered with accelerated deactivation kinetics (Major et al., 2016) - but overall $I_{K s}$ and $I_{K r}$ current densities are not reduced. Consequently, these rabbits exhibit only a partial phenotype with no significant prolongation of whole heart APD (Major et al., 2016; Hornyik et al., 2020), and 


\section{A Ion currents}

$I_{\mathrm{Ks}}$ and $\mathrm{I}_{\mathrm{Kr}}$ currents in WT, LQT1 and LQT2

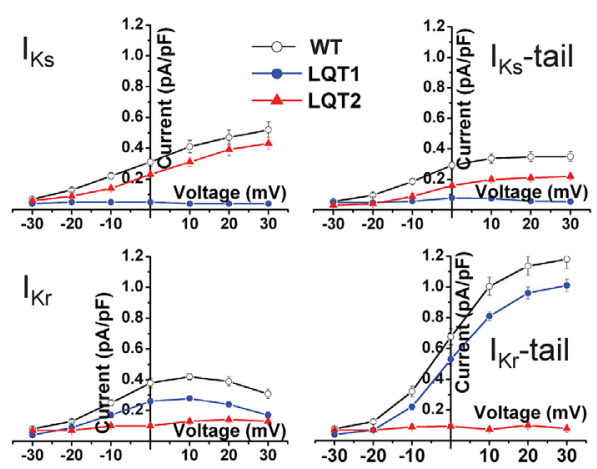

$\mathrm{I}_{\mathrm{Ks}}$ currents in WT and LQT5

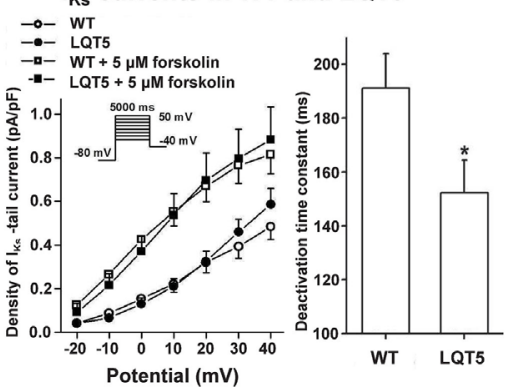

B QT interval
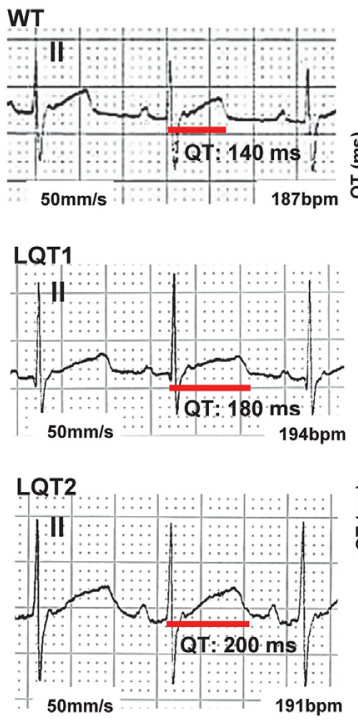

LQT5

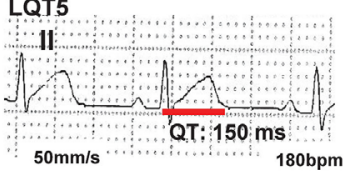

C QT/RR relationship QT/RR ratio in WT, LQT1 and LQT2
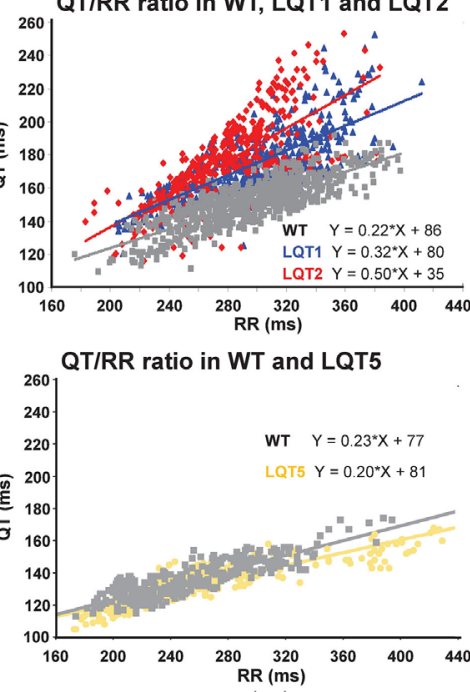

D Spontaneous TdP in LQT2

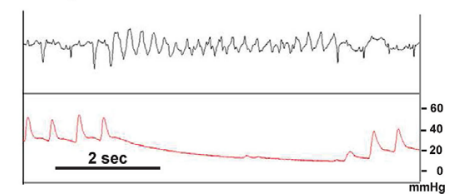

FIGURE 3 | Baseline electrical characteristics of transgenic LQTS rabbits. (A) Upper panel: IV-curves of $I_{\mathrm{Ks}}$ steady (left)/tail (right) and $I_{\mathrm{Kr}}$ steady (left)/tail (right) in cardiomyocytes isolated from wild-type (WT), LQT1, and LQT2 rabbit hearts, indicating loss of $I_{\mathrm{Ks}}$ in LQT1 and loss of $I_{\mathrm{Kr}}$ in LQT2 [modified from (Brunner et al., 2008)]. Lower panel: IV-curves of $\mathrm{I}_{\mathrm{ks}}$ in absence and presence of $5 \mu \mathrm{M}$ forskolin in WT or transgenic LQT5 rabbit ventricular myocytes. Bar diagrams illustrate a reduced deactivation time constant in transgenic LQT5 ventricular myocytes [modified from (Major et al., 2016)]. (B) Representative ECG tracings indicating differences in QT interval in WT, LQT1, LQT2, and LQT5 rabbits [ECG from WT, LQT1 and LQT2 modified from (Brunner et al., 2008)]. (C) QT/RR relationship assessed with telemetric ECG in free moving rabbits: WT, LQT1, and LQT2 in upper panel [modified from (Brunner et al., 2008)], in lower panel in WT and LQT5 [modified from (Hornyik et al., 2020)]. (D) ECG and blood pressure tracing of LQT2 rabbit with spontaneous ventricular torsade-de-pointes (TdP) tachycardia [modified from (Brunner et al., 2008)]. * ${ }^{*}<0.05$ vs. WT.

only a very slightly prolonged QT interval at baseline without changes in QT/RR ratio (Major et al., 2016; Hornyik et al., 2020) (Figures 3A-C), but exhibit an increased short-term beat-tobeat variability of the QT (Major et al., 2016). Due to their reduced repolarization reserve, the phenotype can be augmented by the $I_{\mathrm{Kr}}$-blocking drug dofetilide, which further increased short-term variability of QT and promoted drug-induced VT (Major et al., 2016).

Studies in transgenic LQT1 and LQT2 rabbits highlight the major role of an enhanced (spatial and temporal) dispersion of repolarization in LQTS-related arrhythmogenesis: in LQT2 rabbit hearts, an increased spatial dispersion of APD was observed throughout left and right ventricles (Brunner et al., 2008; Odening et al., 2013) (Figure 4A). Dispersion of repolarization can also occur in a dynamic spatio-temporal fashion with pronounced beat-to-beat alternations and "out-ofphase" heterogeneities between adjacent regions, the so-called "discordant alternans". In transgenic LQT2 rabbit hearts, this discordant alternans developed at physiological heart rates and preceded VT/VF formation (Ziv et al., 2009). VT/VF were easily inducible with LV epicardial stimulation (Brunner et al., 2008), and, importantly, LQT2 rabbits even developed spontaneous polymorphic VT and SCD (Brunner et al., 2008; Odening et al., 2012b), thus representing the first transgenic animal models mimicking the complete electrical phenotype of LQT2. Transgenic LQT1 rabbits with a more homogeneously prolonged APD without substantial dispersion of repolarization within the LV at physiological/normal heart rates, in contrast, developed no spontaneous VT or SCD (Brunner et al., 2008). When LQT1 hearts were further stressed, however, by continuous tachypacing or AV-ablation to induce cardiac tachymyopathy (Lau et al., 2015), or complete AV-block (Kim et al., 2015), respectively, APD dispersion increased, spatially discordant alternans developed and VT/VF was easily inducible or occurred spontaneously. Transgenic LQT5 rabbits demonstrated an increased apico-basal APD heterogeneity compared to healthy WT hearts at baseline-despite their overall "normal" APD (Hornyik et al., 2020).

In addition to increased temporal instability and regional heterogeneity of repolarization that form the electrical "substrate" that facilitates re-entry formation, an increased sympathetic nervous system activity serves as "trigger" for 
A Substrate: Increased APD heterogeneity predisposes to reentry formation and VT/VF
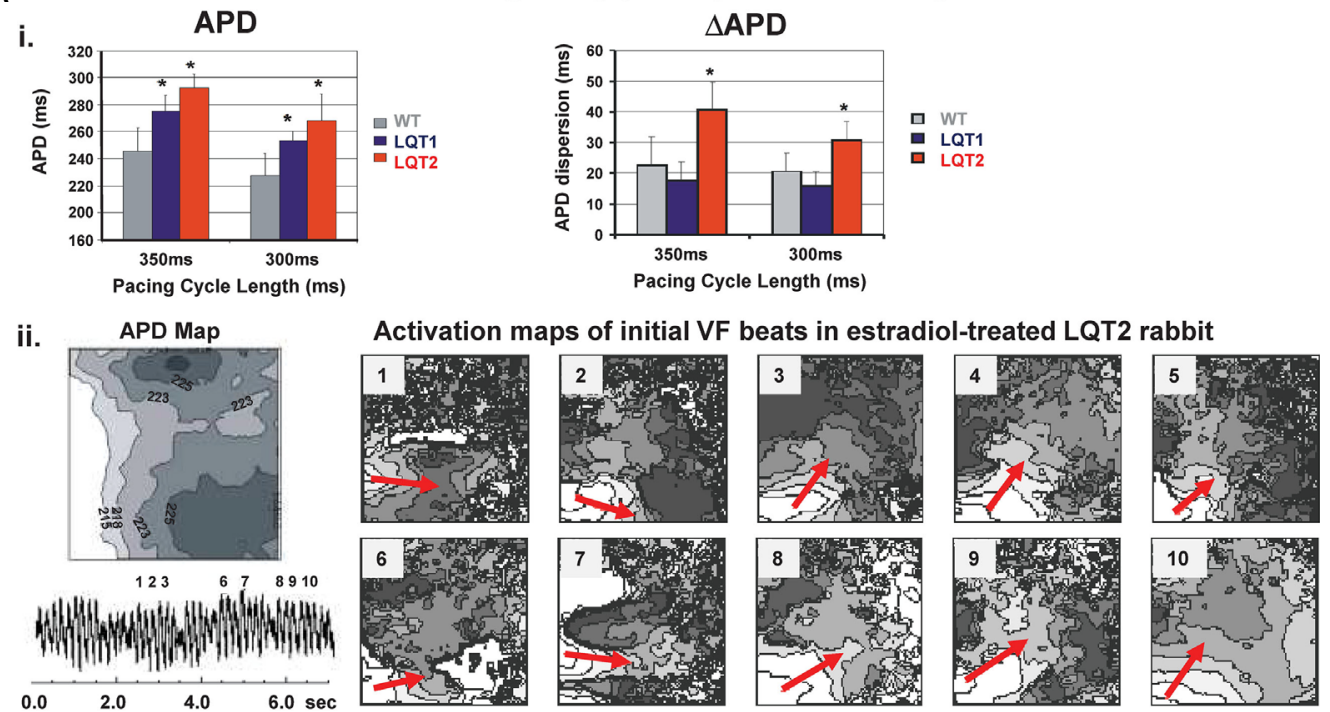

B Trigger: Isoproterenol induces early afterdepolarizations
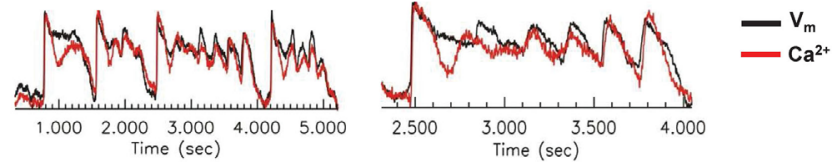

FIGURE 4 | Mechanisms of arrhythmogenesis in transgenic LQT2 rabbits. (A) Upper panel (i): Bar graphs of action potential durations (APD) and dispersion of APD $(\triangle \mathrm{APD})$ in Langendorff-perfused hearts of WT, LQT1, and LQT2 rabbits indicate longer APD and increased APD dispersion in LQT2 hearts, ${ }^{*} \mathrm{p}<0.05$ [modified from (Brunner et al., 2008)]. Lower panel (ii): optical mapping APD map (left; indicated are isochrones of APD, in ms) and activation maps (right) of initial beats of ventricular tachycardia/fibrillation (VF) in an estradiol-treated LQT2 heart indicate reentry formation (indicated by red arrows) in line with the regional APD heterogeneities [modified from (Odening et al., 2012b)]. (B) Representative trace of $\mathrm{Ca}^{2+}$ oscillations and early afterdepolariaztion (EAD) in estradiol-treated LQT2 rabbit heart after AV-node ablation and bolus application of isoproterenol (140 nM). Black line indicates changes in voltage fluorescence signal (Vm); red line indicates changes in $\mathrm{Ca}^{2+}$ signal [modified from (Odening et al., 2012b)].

EADs in long QT-related arrhythmogenesis (Antzelevitch, 2007; Brunner et al., 2008; Ziv et al., 2009). In LQT2 cardiomyocytes, beta-adrenergic stimulation related EADs developed during sudden sympathetic surge (Figure 4B), while continuous perfusion with beta-agonist isoproterenol prevented EAD formation (Brunner et al., 2008; Liu et al., 2012; Odening et al., 2012b). In LQT1 cardiomyocytes, in contrast, continuous betaadrenergic stimulation facilitated the occurrence of EADs (Liu et al., 2012). Different time courses in sympathetic activation of cardiac ion currents may explain why different sympathetic modes (sudden surge vs. continuous activation) are associated with arrhythmia formation in different genotypes of LQTS: upon sympathetic stimulation, beta-1 receptor mediated activation of $I_{\mathrm{Ca}, \mathrm{L}}-$ that may elicit EADs - is faster than the activation of $I_{\mathrm{Ks}}-$ that shortens APD in LQT2 and acts as anti-arrhythmic mechanism upon continuous adrenergic stimulation in LQT2. In addition, different modes of arrhythmia initiation and maintenance in different LQTS genotypes were identified. While in LQT2, reentry formation played an important role (Brunner et al., 2008), in LQT1 hearts, a novel mechanistic concept of LQTS-related arrhythmogenesis was identified: arrhythmia was initiated by focal excitations arising particularly from the RV and was maintained by multiple shifting excitation foci and bi-excitability (Kim et al., 2015).

Similarly, as in the LQT5 rabbit models, the phenotype and proarrhythmia could be augmented by ion channel blocking drugs and endogenous factors (as highlighted in the following subchapters).

\section{Pro-Arrhythmic Effects of Endogenous Factors (Hormones and Metabolites) in Transgenic LQTS Rabbit Models With Impaired Repolarization Reserve}

Pronounced sex differences in arrhythmic risk have been identified in patients with congenital and acquired, drug-induced LQTS with a higher risk for cardiac arrhythmic events in women after puberty than men (Lehmann et al., 1996; Locati et al., 1998; Benton et al., 2000; Wolbrette, 2003; Gowda et al., 2004; Yang and Clancy, 2011). Moreover, while the risk for long QT-related arrhythmia is reduced during pregnancy (Seth et al., 2007), it is particularly high risk during the postpartum (particularly in LQT2 patients) (Sauer et al., 2007). In addition, more pronounced QT-prolongation and 
arrhythmias are observed during luteal than follicular phases of the menstrual cycle (Rodriguez et al., 2001), strongly suggesting that changing sex hormone levels may affect LQTS-related arrhythmogenesis. This has consequences for proarrhythmia research, as female animal models might be particularly sensitive in detecting potential ion channel-blocking properties of drug candidates.

In transgenic LQT2 rabbits, spontaneous ventricular arrhythmia and SCD also often occurred during postpartum (Brunner et al., 2008; Odening et al., 2012b), suggesting the existence of similar arrhythmia-triggering mechanisms as in human LQTS patients. In these models, estradiol exerted a pro-arrhythmic effect with an increased incidence of lethal polymorphic TdP due to changes in APD dispersion and increased EAD formation upon proarrhythmic sympathetic stimuli, while progesterone had an antiarrhythmic, protective effect that was based on a shortening of cardiac refractoriness, a reduced formation of EAD, and stabilizing $\mathrm{Ca}^{2+}$ effects (decreased $I_{\mathrm{Ca}, \mathrm{L}}$ density, increased SERCA expression) (Odening et al., 2012b). These studies suggest that progesteronebased therapies may be considered as novel anti-arrhythmic approaches in female LQTS patients; and might be considered as therapeutic add-on in cases of severe drug-induced long-QT related proarrhythmia (Odening et al., 2012b). As estradiol-treated hearts are particularly sensitive to proarrhythmia, their use in proarrhythmia research, in contrast, might increase sensitivity to identify candidates with a pro-arrhythmic potential.

Similarly, the postpartum-related hormones oxytocin and prolactin decreased $I_{\mathrm{Ks}}$ current densities, thereby prolonging the APD/QT further and predisposing the heart to arrhythmias (Odening et al., 2019).

Hormones as well as other endogenous factors such as certain metabolites may impact on repolarization reserve: it has been demonstrated that (genetic) metabolic disturbances such as propionic acidemia can also cause acquired LQTS (Kakavand et al., 2006; Baumgartner et al., 2007; Jameson and Walter, 2008), thus rendering patients at increased risk for additional drug-induced proarrhythmia. Using rabbit models of LQTS, we could identify a propionic acid-induced reduction of $I_{\mathrm{Ks}}$ current densities as underlying mechanism (Bodi et al., 2016).

\section{A Changes in in vivo pro-arrhythmia markers}
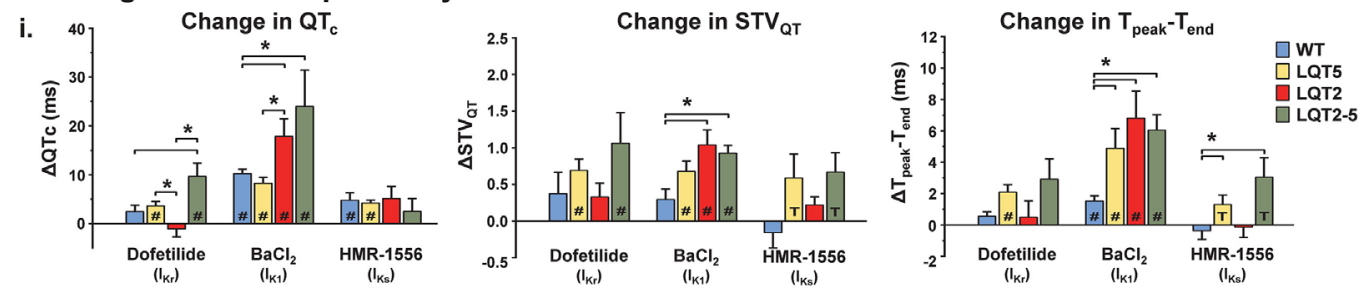

ii. Change in QT-index by $\mathrm{I}_{\mathrm{K} 1}$-bocker Midazolam

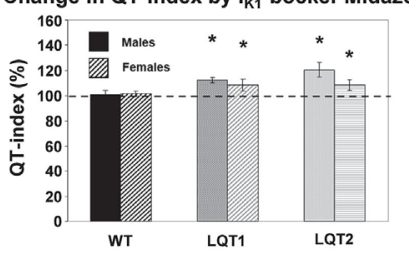

iii. Change in $\mathrm{STV}_{\mathrm{QT}}$ by Dofetilide

B Changes in ex vivo pro-arrhythmia markers
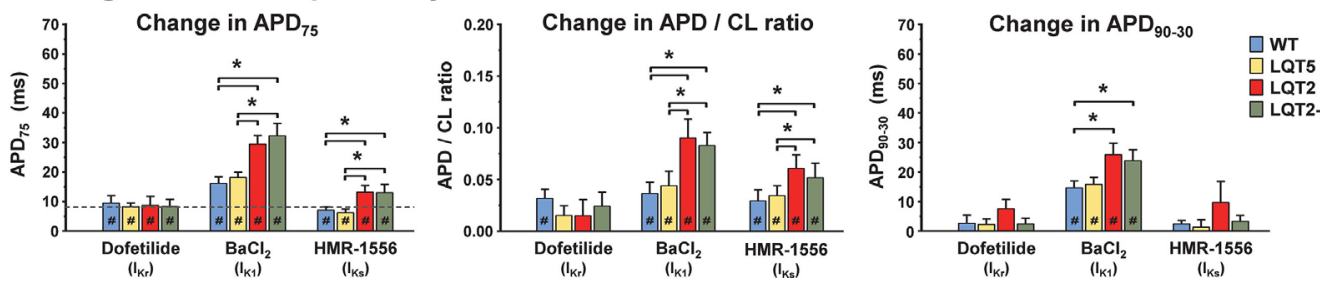

FIGURE 5 | Pro-arrhythmic drug-effects in transgenic LQTS rabbit models: changes in pro-arrhythmia markers. (A) Changes in in vivo pro-arrhythmia markers. (i.) Bar graphs show changes in QTc, STV $\mathrm{QT}_{\mathrm{T}}$, and $\mathrm{T}_{\text {peak }}-\mathrm{T}_{\text {end }}$ in anaesthetized animals after i.m. injection of $\mathrm{I}_{\mathrm{Kr}}, \mathrm{I}_{\mathrm{K} 1}$, and $\mathrm{I}_{\mathrm{Ks}}-\mathrm{blockers}$ dofetilide, BaCl $\mathrm{I}_{2}$, HMR-1556, respectively in WT, LQT2, LQT5, and LQT2-5 rabbits [modified from (Hornyik et al., 2020)]. ${ }^{*} \mathrm{p}<0.05$ inter-genotype comparison, ${ }^{\#} \mathrm{p}<0.05$ vs. baseline, $\mathrm{T}$ trend $\mathrm{p}<0.1$ vs. baseline. (ii.) $I_{\mathrm{K} 1}$-blocker midazolam-induced change in heart-rate corrected QT-index in free-moving male (solid bars) and female (hatched bars) WT, LQT1, and LQT2 rabbits is also shown. The dashed line represents the mean QT indexes in free-moving rabbits obtained with the genotype-specific correction formula (=100\%) [modified from (Odening et al., 2008)]. * $\mathrm{p}<0.05$ vs. free-moving rabbits of the same genotype. (iii.) Bar graphs indicate $\mathrm{I}_{\mathrm{Kr}}$-blocker dofetilideinduced increase in STV $\mathrm{QT}_{\mathrm{T}}$ in WT and LQT5 animals [modified from (Major et al., 2016)]. Bsl, baseline; Dof, dofetilide. ${ }^{*} p<0.05$ inter-genotype comparison, " $p<0.05$ vs. baseline. (B) Changes in ex vivo pro-arrhythmia markers. Bar graphs of changes in action potential duration ( $\triangle \mathrm{APD} 75)$, action potential duration/stimulation cycle length ratio ( $\triangle \mathrm{APD} / \mathrm{CL}$ ratio and action potential triangulation ( $\triangle \mathrm{APD} 90-30)$ after 10 min perfusion with $\mathrm{I}_{\mathrm{Kr}}$, $\mathrm{I}_{\mathrm{K} 1}$ and $\mathrm{I}_{\mathrm{Ks}}-\mathrm{blockers}$ dofetilide, BaCl 2 and $\mathrm{HMR}-1556$, respectively in WT, LQT2, LQT5, and LQT2-5 rabbits. " $p<0.05$ inter-genotype comparison, ${ }^{*} p<0.05$ vs. baseline [modified from (Hornyik et al., 2020)]. 


\section{Transgenic LQTS Rabbit Models for Better Detection of Drug-Induced Ventricular Arrhythmias}

Drug-induced proarrhythmia is based on regionally heterogeneous prolongation of cardiac repolarization caused by various groups of drugs blocking multiple ion channels. As it most-often occurs in patients with reduced repolarization reserve (see above), the use of various transgenic LQTS rabbit models (Brunner et al., 2008; Major et al., 2016) with increased sensitivities to potassium channel blocking effects and different degrees of impairment in their cardiac repolarization reserve, is expected to provide more reliable, and more thorough detection of (multi-channel-based) drug-induced ventricular arrhythmias.

Indeed, it has been shown that LQT1 rabbits lacking $I_{\mathrm{Ks}}$ and LQT5 rabbits with impaired $I_{\mathrm{Ks}}$ function were particularly sensitive in identifying $I_{\mathrm{Kr}}$-blocking properties of drugs; while transgenic LQT2 rabbits lacking $\mathrm{I}_{\mathrm{Kr}}$ demonstrated a particularly high sensitivity to $I_{\mathrm{Ks}^{-}}$or $I_{\mathrm{K} 1}$-blocking drugs (Volders et al., 2003; Jost et al., 2005; Odening et al., 2010; Odening et al., 2013; Hornyik et al., 2020) as further outlined in the following subchapters.

\section{Investigation of Drug-Induced Changes in Proarrhythmia Markers in Transgenic LQTS Rabbit Models}

Drug-induced arrhythmia is a relatively rare event, and arrhythmia development as "hard endpoint" cannot be directly studied-especially during "first-in-human" clinical trials. Therefore, model systems with increased susceptibility for proarrhythmia are employed for safety testing and changes in various proarrhythmia markers are monitored to assess the proarrhythmic potential of the investigated/applied drug.

Several biomarkers have been suggested to use for proarrhythmia screening that reflect changes in various aspects of repolarization such as: (i) duration (QTc, APD), (ii) spatial ( $\mathrm{T}_{\text {peak-end, }} \mathrm{APD}$ dispersion), and (iii) temporal dispersion (STV $\mathrm{QT}_{\mathrm{QT}}, \mathrm{QT} / \mathrm{RR}$ steepness, APD restitution) of repolarization (for more details, see previous sections). These were also employed in the different transgenic LQTS rabbit models.

Transgenic LQT2 rabbits demonstrated a high sensitivity to $I_{\mathrm{Ks}^{-}}$or $I_{\mathrm{K} 1}$-blocking anesthetic agents such as isoflurane $\left(I_{\mathrm{Ks}}\right)$ or the anxiolytic sedative midazolam $\left(I_{\mathrm{K} 1}\right)$ as demonstrated by a particularly pronounced prolongation of QT and heart-rate corrected QT index as compared to healthy rabbits (Odening et al., 2008) (Figure 5A). In addition, a pronounced increase in in vivo ECG proarrhythmia markers $\left(\mathrm{QT}, \mathrm{STV}_{\mathrm{QT}}\right.$, and $\left.\mathrm{T}_{\text {peak-end }}\right)$ and ex vivo monophasic AP related proarrhythmia markers (APD, AP triangulation and APD restitution steepness) indicated higher susceptibility also to other $I_{\mathrm{K} 1}$ and $I_{\mathrm{Ks}}$ blocking compounds $\left(\mathrm{BaCl}_{2}\right.$ and HMR-1556) in transgenic LQT2 and double-transgenic LQT2-5 rabbits (Hornyik et al., 2020) (Figures 5A, B).

LQT1 and LQT5 models; on the other hand, were especially sensitive to $I_{\mathrm{Kr}}$ blockade (dofetilide, E4031, and erythromycin), as demonstrated in vivo by a pronounced increase in QTc, $\mathrm{STV}_{\mathrm{QT}}$, and $\mathrm{T}_{\text {peak-end }}$ and ex vivo by a prolongation of $\mathrm{APD}$ and (in LQT1) APD dispersion (Odening et al., 2010; Ziupa et al., 2014; Major et al., 2016).

\section{Investigation of Ex Vivo Susceptibility to Arrhythmia in Isolated Transgenic LQTS Rabbit Hearts}

The direct assessment of ex vivo arrhythmia development in isolated Langendorff-perfused transgenic LQTS rabbit hearts were first performed by Hornyik et al., using different provocation factors-such as bradycardia, low $\left[\mathrm{K}^{+}\right]_{\mathrm{o}}$, and/or application of $\mathrm{K}^{+}$-channel blockers-that are also crucial in drug-induced proarrhythmia formation in the clinical setting (Hornyik et al., 2020). It was shown that the application of $I_{\mathrm{K} 1^{-}}$ blocker $\mathrm{BaCl}_{2}$ alone already significantly increased the incidence and duration of ventricular extra beats in LQT2 and LQT2-5 hearts (Figure 6A). When the pre-existing temporal, beat-tobeat-QT-instability, and the prolonged, regionally heterogeneous repolarization were even further aggravated by lowering the $\left[\mathrm{K}^{+}\right]_{\mathrm{o}}$, the sensitivity for re-entry formation was increased, leading to significantly longer duration and higher incidence of more malignant type of ventricular arrhythmias (VT and VF) in LQT2 and LQT2-5 but not in healthy WT hearts (Figure 6A). In LQT5 hearts with less pronounced reduction of repolarization reserve, only less severe types of ventricular arrhythmias (bigeminy) were detected. These observations of a higher sensitivity of transgenic LQTS hearts to potassium channel blocking drugs than normal WT hearts suggests that the use of different transgenic LQTS rabbits might help in more reliably detect drug-induced proarrhythmia.

\section{Investigation of In Vivo Susceptibility to Arrhythmia of Transgenic LQTS Rabbits}

High in vivo susceptibility to arrhythmia of transgenic LQTS rabbit models were demonstrated as early as the first characterizations of the models were performed.

In transgenic LQT2 rabbit models, exhibiting regionally heterogeneous prolongation of repolarization, VT and VF easily occurred spontaneously resulting in high SCD rates (Brunner et al., 2008). In addition, a further reduction of repolarization reserve by the $I_{\mathrm{Ks}}$-blocker isoflurane or by the $I_{\mathrm{to}}-/ I_{\mathrm{Ks}}$-blocker propofol led to increased proarrhythmia with a variety of arrhythmic events such as AV 2:1 blocks, T-wave alternans, PVCs, bigeminy, and lethal TdP occurring even during short episodes of anesthesia (Odening et al., 2008) (Figure 6B).

Transgenic LQT1 rabbits with normal/physiological heart rates and/or without organic heart diseases exhibited relatively homogenous prolongation of repolarization in the LV without substantial increase in APD dispersion; therefore, no spontaneous arrhythmias and SCD were detected (Brunner et al., 2008). When the repolarization reserve of LQT1 rabbits were further challenged by continuous tachypacing or AVablation to induce cardiac tachymyopathy (Lau et al., 2015), or complete AV-block (Kim et al., 2015), respectively, however, significant APD dispersion and discordant alternans developed and VT/VF was easily inducible and even occurred spontaneously (Lau et al., 2015). The model also demonstrated the development of pseudo-AV blocks and drug-induced TdP 


\section{A Ex vivo arrhythmia development}
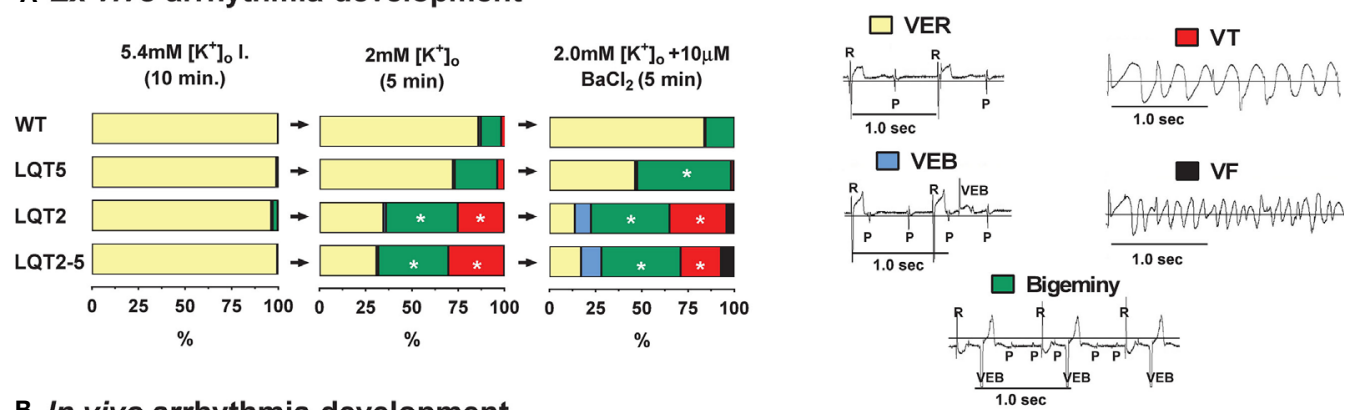

\section{B In vivo arrhythmia development}

i. Dofetilide-induced TdP incidence and duration in WT and LQT5
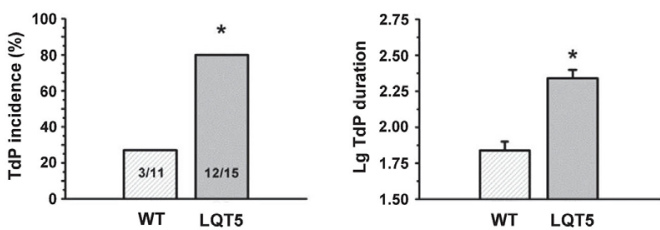

ii. TdP in LQT2 during propofol anesthesia

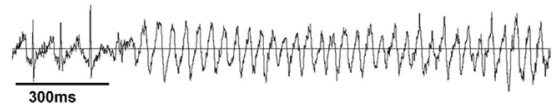

iii. Dofetilide-induced pVT in LQT1

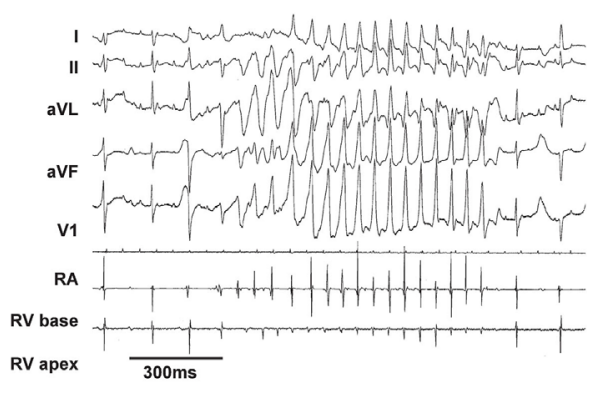

FIGURE 6 | Pro-arrhythmic drug-effects in transgenic LQTS rabbit models: arrhythmia development. (A) Ex vivo arrhythmia development. Graphs indicating the duration (\% of perfusion time) of arrhythmias provoked by perfusing the hearts with low $\left[\mathrm{K}^{+}\right]_{\mathrm{o}}(2 \mathrm{mM}) \mathrm{KH}$, or with combined low $\left[\mathrm{K}^{+}\right]_{\mathrm{o}}(2 \mathrm{mM}) \mathrm{KH}$ and $\mathrm{I}_{\mathrm{K}^{-}}$-blocker $\mathrm{BaCl}_{2}(10 \mu \mathrm{M})$ in WT, LQT5, LQT2 and LQT2-5 animals. Inlets show representative ECG recordings of ventricular escape rhythm (VER), ventricular extra beats (VEB), bigeminy, ventricular tachycardia (VT) and ventricular fibrillation (VF) [modified from (Hornyik et al., 2020)]. ${ }^{*} \mathrm{p}<0.05$ inter-genotype comparison. (B) In vivo arrhythmia development. (i.) Bar graphs of dofetilide-induced incidence (in \%) and log duration of torsade de pointes (TdP) tachycardia in WT and LQT5 rabbits [modified from (Major et al., 2016)]. ${ }^{*} \mathrm{p}<0.05$ inter-genotype comparison. (ii.) Episode of polymorphic TdP tachycardia in female LQT2 rabbit during propofol anesthesia (acquired with telemetric ECG) [modified from (Odening et al., 2008)]. (iii.) Episode of dofetilide-induced pVT in male LQT1 rabbit during episode of alternating AV 2:1/3:1 block [modified from (Odening et al., 2010)].

upon $I_{\mathrm{Kr}}$-blockade by dofetilide and E4031 (Odening et al., 2010; Ziupa et al., 2014; Major et al., 2016; Ziupa et al., 2019) (Figure 6B).

The recently generated LQT5 model with slight reduction in $I_{\mathrm{Ks}}$ function similarly demonstrated more pronounced $I_{\mathrm{Kr}^{-}}$ blocker dofetilide induced TdP formation in vivo than healthy WT rabbits (Major et al., 2016) (Figure 6B).

\section{Limitations of the Currently Available Models and Outlook}

As the "dominant-negative" transgenic strategy was used to generate the LQTS rabbits, instead of a rabbit gene "knockout"/human transgene "knock in" approach; these models are genetically distinct from LQTS patients. Newly emerging genetic engineering techniques such as CRISPR-cas [as described in details in (Bosze et al., 2016)] may help to develop novel-also genetically closer-animal models for these human diseases. As currently available models demonstrate a LQTS phenotype, however, with different degrees of reduction in repolarization reserve and increased susceptibility to arrhythmia both spontaneously and particularly upon drug-induced ion channel blockade, they could still represent valuable models for proarrhythmia safety testing in the context of reduced repolarization reserve.

Furthermore, compensatory electro-mechanical adaptation of cardiomyocytes in response to the altered function ("cardiac remodeling") can also show species differences that could influence their arrhythmia sensitivity. In transgenic LQTS mice, for example, the observed compensatory upregulation of non-affected potassium currents limit their use in identifying repolarizing prolonging - potentially pro-arrhythmic —agents, as opposed to transgenic LQTS rabbits, in which parallel decrease in reciprocal repolarizing current(s) was seen (Brunner et al., 2008) that even further increased the sensitivity of these models to detect drug-induced proarrhythmia. Currently, very little is known about the nature and extent of these compensatory remodeling processes in human diseases with impaired cardiac repolarization reserve; therefore, it is not known, which animal model mimics most accurately human pathophysiology from this aspect.

In spite of similarities in cardiac ion channels in rabbits and humans, cardiac repolarization is still conveyed through ion channels with slightly different biophysiological characteristics in each species; therefore, caution has to be applied when 
translating findings based on data from experimental animal models into humans.

Current animal models focus on the detection of repolarization prolonging pro-arrhythmic effects. Drug-induced proarrhythmia may, however, also occur upon pathologically pronounced acceleration/shortening of cardiac repolarization (Malik, 2016). Here, novel models such as the transgenic short QT syndrome rabbit model (Odening et al., 2019), may be particularly useful for the detection of these pro-arrhythmic drug properties.

Further improvement of current in silico proarrhythmia screening capabilities by integrating experimental in vivo, whole heart, cellular, and ion channel data into computational models are highly warranted (Sager et al., 2014; Colatsky et al., 2016), and could potentially lead to better assessment of mutation-specific aspects of a wide range of cardiac channelopathies, since currently available animal models mimicking cardiac channelopathies are very limited.

Importantly, the future use of patient-specific and/or diseasespecific human induced pluripotent stem cell derived cardiomyocytes (iPSC-CM) has the potential to become a relevant additional patient/disease-specific in vitro safety screening platform to test the pro-arrhythmic potential of novel drug candidates (Mehta et al., 2013; Sager et al., 2014; Colatsky et al., 2016).

\section{AUTHOR CONTRIBUTIONS}

IB wrote the manuscript and designed the figures. TH wrote the manuscript and designed the figures. $\mathrm{MB}$ and GK generated the LQT1 and LQT2 rabbits and edited the manuscript. KO wrote the manuscript and designed the figures.

\section{FUNDING}

This work was supported by a grant from the German Heart Foundation (F/02/14) and grants from the German Research Foundation (OD 86/6-1, and BR 2107/4-1) to KO and the Hungarian National Research, Development and Innovation Office (NKFIH K128851) and Ministry of Human Capacities (EFOP-3.6.2-16-2017-00006) to IB.

\section{REFERENCES}

Amos, G. J., Abrahamsson, C., Duker, G., Hondeghem, L., Palmer, M., and Carlsson, L. (2001). Potassium and calcium current blocking properties of the novel antiarrhythmic agent $\mathrm{H}$ 345/52: implications for proarrhythmic potential. Cardiovasc. Res. 49, 351-360. doi: 10.1016/S0008-6363(00)00259-5

Anderson, M. E. (2006). QT interval prolongation and arrhythmia: an unbreakable connection? J. Intern. Med. 259, 81-90. doi: 10.1111/j.1365-2796.2005.01580.x

Ando, F., Kuruma, A., and Kawano, S. (2011). Synergic effects of beta-estradiol and erythromycin on hERG currents. J. Membr. Biol. 241, 31-38. doi: $10.1007 /$ s00232-011-9360-z

Antoons, G., Oros, A., Beekman, J. D., Engelen, M. A., Houtman, M. J., Belardinelli, L., et al. (2010). Late na(+) current inhibition by ranolazine reduces torsades de pointes in the chronic atrioventricular block dog model. J. Am. Coll. Cardiol. 55, 801-809. doi: 10.1016/j.jacc.2009.10.033

Antzelevitch, C. (2007). Role of spatial dispersion of repolarization in inherited and acquired sudden cardiac death syndromes. Am. J. Physiol. Heart Circ. Physiol. 293, H2024-H2038. doi: 10.1152/ajpheart.00355.2007

Antzelevitch, C. (2008). Drug-induced spatial dispersion of repolarization. Cardiol. J. 15, 100-121.

Authier, S., Pugsley, M. K., Koerner, J. E., Fermini, B., Redfern, W. S., Valentin, J. P., et al. (2017). Proarrhythmia liability assessment and the comprehensive in vitro Proarrhythmia Assay (CiPA): An industry survey on current practice. J. Pharmacol. Toxicol. Methods 86, 34-43. doi: 10.1016/j.vascn.2017.02.021

Baczko, I., Jost, N., Virag, L., Bosze, Z., and Varro, A. (2016). Rabbit models as tools for preclinical cardiac electrophysiological safety testing: Importance of repolarization reserve. Prog. Biophys. Mol. Biol. 121, 157-168. doi: 10.1016/ j.pbiomolbio.2016.05.002

Barbhaiya, C., Po, J. R., Hanon, S., and Schweitzer, P. (2013). Tpeak - Tend and Tpeak - Tend /QT ratio as markers of ventricular arrhythmia risk in cardiac resynchronization therapy patients. Pacing Clin. Electrophysiol. 36, 103-108. doi: $10.1111 /$ pace.12031

Baumert, M., Porta, A., Vos, M. A., Malik, M., Couderc, J. P., Laguna, P., et al. (2016). QT interval variability in body surface ECG: measurement, physiological basis, and clinical value: position statement and consensus guidance endorsed by the European Heart Rhythm Association jointly with the ESC Working Group on Cardiac Cellular Electrophysiology. Europace 18, 925-944. doi: 10.1093/europace/euv405

Baumgartner, D., Scholl-Burgi, S., Sass, J. O., Sperl, W., Schweigmann, U., Stein, J. I., et al. (2007). Prolonged QTc-intervals and decreased left ventricular contractility in

patients with propionic acidemia. J. Pediatr. 150, 192-197. doi: 10.1016/ j.jpeds.2006.11.043

Belardinelli, L., Antzelevitch, C., and Vos, M. A. (2003). Assessing predictors of drug-induced torsade de pointes. Trends Pharmacol. Sci. 24, 619-625. doi: 10.1016/j.tips.2003.10.002

Benton, R. E., Sale, M., Flockhart, D. A., and Woosley, R. L. (2000). Greater quinidine-induced QTc interval prolongation in women. Clin. Pharmacol. Ther. 67, 413-418. doi: 10.1067/mcp.2000.105761

Blenck, C. L., Harvey, P. A., Reckelhoff, J. F., and Leinwand, L. A. (2016). The Importance of Biological Sex and Estrogen in Rodent Models of Cardiovascular Health and Disease. Circ. Res. 118, 1294-1312. doi: 10.1161/ CIRCRESAHA.116.307509

Bodi, I., Grunert, S. C., Becker, N., Stoelzle-Feix, S., Spiekerkoetter, U., Zehender, M., et al. (2016). Mechanisms of acquired Long QT syndrome in patients with propionic academia. Heart Rhythm. 13, 1335-1345. doi: 10.1016/ j.hrthm.2016.02.003

Bosze, Z., Major, P., Baczko, I., Odening, K. E., Bodrogi, L., Hiripi, L., et al. (2016). The potential impact of new generation transgenic methods on creating rabbit models of cardiac diseases. Prog. Biophys. Mol. Biol. 121, 123-130. doi: 10.1016/j.pbiomolbio.2016.05.007

Bouder, F. (2007). A case study of long QT regulation: A regulatory tennis game across the Atlantic. J. Risk Res. 10, 385-412. doi: 10.1080/13669870 701270903

Brunner, M., Guo, W., Mitchell, G. F., Buckett, P. D., Nerbonne, J. M., and Koren, G. (2001). Characterization of mice with a combined suppression of I(to) and I (K,slow). Am. J. Physiol. Heart Circ. Physiol. 281, H1201-H1209. doi: 10.1152/ ajpheart.2001.281.3.H1201

Brunner, M., Peng, X., Liu, G. X., Ren, X. Q., Ziv, O., Choi, B. R., et al. (2008). Mechanisms of cardiac arrhythmias and sudden death in transgenic rabbits with long QT syndrome. J. Clin. Invest. 118, 2246-2259. doi: 10.1172/JCI33578

Carlsson, L., Andersson, B., Linhardt, G., and Lofberg, L. (2009). Assessment of the ion channel-blocking profile of the novel combined ion channel blocker AZD1305 and its proarrhythmic potential versus dofetilide in the methoxamine-sensitized rabbit in vivo. J. Cardiovasc. Pharmacol. 54, 82-89. doi: 10.1097/FJC.0b013e3181ac62c9

Carlsson, L. (2001). Drug-induced torsade de pointes: the perspectives of industry. Eur. Heart J. Suppl. 3, K114-K120. doi: 10.1016/S1520-765X(01)90016-1

Carlsson, L. (2008). The anaesthetised methoxamine-sensitised rabbit model of torsades de pointes. Pharmacol. Ther. 119, 160-167. doi: 10.1016/ j.pharmthera.2008.04.004 
Cavero, I., and Holzgrefe, H. (2014). Comprehensive in vitro Proarrhythmia Assay, a novel in vitro/in silico paradigm to detect ventricular proarrhythmic liability: a visionary 21st century initiative. Expert Opin. Drug Saf. 13, 745-758. doi: $10.1517 / 14740338.2014 .915311$

Chen, G., Yang, X., Alber, S., Shusterman, V., and Salama, G. (2011). Regional genomic regulation of cardiac sodium-calcium exchanger by oestrogen. J. Physiol. 589, 1061-1080. doi: 10.1113/jphysiol.2010.203398

Choi, B. R., Burton, F., and Salama, G. (2002). Cytosolic Ca2+ triggers early afterdepolarizations and Torsade de Pointes in rabbit hearts with type 2 long QT syndrome. J. Physiology-London 543, 615-631. doi: 10.1113/ jphysiol.2002.024570

Choi, B. R., Li, W., Terentyev, D., Kabakov, A. Y., Zhong, M., Rees, C. M., et al. (2018). Transient Outward K(+) Current (Ito) Underlies the Right Ventricular Initiation of Polymorphic Ventricular Tachycardia in a Transgenic Rabbit Model of Long-QT Syndrome Type 1. Circ. Arrhythm. Electrophysiol. 11, e005414. doi: 10.1161/CIRCEP.117.005414

Colatsky, T., Fermini, B., Gintant, G., Pierson, J. B., Sager, P., Sekino, Y., et al. (2016). The Comprehensive in Vitro Proarrhythmia Assay (CiPA) initiative Update on progress. J. Pharmacol. Toxicol. Methods 81, 15-20. doi: 10.1016/ j.vascn.2016.06.002

Crumb, W. J.Jr., Vicente, J., Johannesen, L., and Strauss, D. G. (2016). An evaluation of 30 clinical drugs against the comprehensive in vitro proarrhythmia assay (CiPA) proposed ion channel panel. J. Pharmacol. Toxicol. Methods 81, 251-262. doi: 10.1016/j.vascn.2016.03.009

Danker, T., and Moller, C. (2014). Early identification of hERG liability in drug discovery programs by automated patch clamp. Front. Pharmacol. 5, 203. doi: 10.3389/fphar.2014.00203

Darpo, B. (2001). Spectrum of drugs prolonging QT interval and the incidence of torsades de pointes. Eur. Heart J. Suppl. 3, K70-K80. doi: 10.1016/S1520-765X (01)90009-4

Decker, J. A., Rossano, J. W., Smith, E. O., Cannon, B., Clunie, S. K., Gates, C., et al. (2009). Risk factors and mode of death in isolated hypertrophic cardiomyopathy in children. J. Am. Coll. Cardiol. 54, 250-254. doi: 10.1016/j.jacc.2009.03.051

Derangeon, M., Montnach, J., Baro, I., and Charpentier, F. (2012). Mouse Models of SCN5A-Related Cardiac Arrhythmias. Front. Physiol. 3, 210. doi: 10.3389/ fphys.2012.00210

Dhein, S., Perlitz, F., and Mohr, F. W. (2008). An in vitro model for assessment of drug-induced torsade de pointes arrhythmia : effects of haloperidol and dofetilide on potential duration, repolarization inhomogeneities, and torsade de pointes arrhythmia. Naunyn Schmiedebergs Arch. Pharmacol. 378, 631-644. doi: 10.1007/s00210-008-0329-0

Diness, T. G., Yeh, Y. H., Qi, X. Y., Chartier, D., Tsuji, Y., Hansen, R. S., et al. (2008). Antiarrhythmic properties of a rapid delayed-rectifier current activator in rabbit models of acquired long QT syndrome. Cardiovasc. Res. 79, 61-69. doi: $10.1093 / \mathrm{cvr} / \mathrm{cvn} 075$

Drici, M. D., Burklow, T. R., Haridasse, V., Glazer, R. I., and Woosley, R. L. (1996). Sex hormones prolong the QT interval and downregulate potassium channel expression in the rabbit heart. Circulation 94, 1471-1474. doi: 10.1161/ 01.CIR.94.6.1471

Dutta, S., Minchole, A., Zacur, E., Quinn, T. A., Taggart, P., and Rodriguez, B. (2016). Early afterdepolarizations promote transmural reentry in ischemic human ventricles with reduced repolarization reserve. Prog. Biophys. Mol. Biol. 120, 236-248. doi: 10.1016/j.pbiomolbio.2016.01.008

Echt, D. S., Liebson, P. R., Mitchell, L. B., Peters, R. W., Obias-Manno, D., Barker, A. H., et al. (1991). Mortality and morbidity in patients receiving encainide, flecainide, or placebo. The Cardiac Arrhythmia Suppression Trial. N. Engl. J. Med. 324, 781-788. doi: 10.1056/NEJM199103213241201

Eisenberg, S. J., Scheinman, M. M., Dullet, N. K., Finkbeiner, W. E., Griffin, J. C., Eldar, M., et al. (1995). Sudden cardiac death and polymorphous ventricular tachycardia in patients with normal QT intervals and normal systolic cardiac function. Am. J. Cardiol. 75, 687-692. doi: 10.1016/S0002-9149(99)80654-7

El-Sherif, N., and Turitto, G. (1999). The long QT syndrome and torsade de pointes. Pacing Clin. Electrophysiol. 22, 91-110. doi: 10.1111/j.15408159.1999.tb00305.x

Fabritz, L., Kirchhof, P., Franz, M. R., Nuyens, D., Rossenbacker, T., Ottenhof, A., et al. (2003). Effect of pacing and mexiletine on dispersion of repolarisation and arrhythmias in DeltaKPQ SCN5A (long QT3) mice. Cardiovasc. Res. 57, 10851093. doi: $10.1016 /$ S0008-6363(02)00839-8
Farkas, A. S., and Nattel, S. (2010). Minimizing repolarization-related proarrhythmic risk in drug development and clinical practice. Drugs 70, 573-603. doi: 10.2165/11535230-000000000-00000

Farkas, A. S., Acsai, K., Toth, A., Dezsi, L., Orosz, S., Forster, T., et al. (2006). Importance of extracardiac alpha1-adrenoceptor stimulation in assisting dofetilide to induce torsade de pointes in rabbit hearts. Eur. J. Pharmacol. 537, 118-125. doi: 10.1016/j.ejphar.2006.03.014

Fedida, D., and Giles, W. R. (1991). Regional variations in action potentials and transient outward current in myocytes isolated from rabbit left ventricle. J. Physiol. 442, 191-209. doi: 10.1113/jphysiol.1991.sp018789

Fenichel, R. R., Malik, M., Antzelevitch, C., Sanguinetti, M., Roden, D. M., Priori, S. G., et al. (2004). Drug-induced torsades de pointes and implications for drug development. J. Cardiovasc. Electrophysiol. 15, 475-495. doi: 10.1046/j.15408167.2004.03534.x

Ferdinandy, P., Baczko, I., Bencsik, P., Giricz, Z., Gorbe, A., Pacher, P., et al. (2019). Definition of hidden drug cardiotoxicity: paradigm change in cardiac safety testing and its clinical implications. Eur. Heart J. 40, 1771-1777. doi: 10.1093/eurheartj/ehy365

Food, and Drug Administration, H.H.S (2005a). International Conference on Harmonisation; guidance on E14 Clinical Evaluation of QT/QTc Interval Prolongation and Proarrhythmic Potential for Non-Antiarrhythmic Drugs; availability. Notice. Fed. Regist. 70, 61134-61135.

Food, and Drug Administration, H.H.S (2005b). International Conference on Harmonisation; guidance on S7B Nonclinical Evaluation of the Potential for Delayed Ventricular Repolarization (QT Interval Prolongation) by Human Pharmaceuticals; availability. Notice. Fed. Regist. 70, 61133-61134.

Furukawa, T., and Kurokawa, J. (2008). Non-genomic regulation of cardiac ion channels by sex hormones. Cardiovasc. Hematol. Disord. Drug Targets 8, 245251. doi: $10.2174 / 187152908786786160$

Gill, G. V., Woodward, A., Casson, I. F., and Weston, P. J. (2009). Cardiac arrhythmia and nocturnal hypoglycaemia in type 1 diabetes-the 'dead in bed' syndrome revisited. Diabetologia 52, 42-45. doi: 10.1007/s00125-008-1177-7

Giunti, S., Bruno, G., Lillaz, E., Gruden, G., Lolli, V., Chaturvedi, N., et al. (2007). Incidence and risk factors of prolonged QTc interval in type 1 diabetes: the EURODIAB Prospective Complications Study. Diabetes Care 30, 2057-2063. doi: $10.2337 / \mathrm{dc} 07-0063$

Gowda, R. M., Khan, I. A., Punukollu, G., Vasavada, B. C., Sacchi, T. J., and Wilbur, S. L. (2004). Female preponderance in ibutilide-induced torsade de pointes. Int. J. Cardiol. 95, 219-222. doi: 10.1016/j.ijcard.2003.04.034

Grandy, S. A., Trepanier-Boulay, V., and Fiset, C. (2007). Postnatal development has a marked effect on ventricular repolarization in mice. Am. J. Physiol. Heart Circ. Physiol. 293, H2168-H2177. doi: 10.1152/ajpheart.00521.2007

Guerard, N., Jordaan, P., and Dumotier, B. (2014). Analysis of unipolar electrograms in rabbit heart demonstrated the key role of ventricular apicobasal dispersion in arrhythmogenicity. Cardiovasc. Toxicol. 14, 316328. doi: 10.1007/s12012-014-9254-2

Hancox, J. C., Mcpate, M. J., El Harchi, A., and Zhang, Y. H. (2008). The hERG potassium channel and hERG screening for drug-induced torsades de pointes. Pharmacol. Ther. 119, 118-132. doi: 10.1016/j.pharmthera.2008.05.009

Harken, A. H., Simson, M. B., Haselgrove, J., Wetstein, L., Harden, W., and Barlow, C. H. (1981). Early ischemia after complete coronary ligation in the rabbit, dog, pig, and monkey. Am. J. Physiol. 241, H202-H210. doi: 10.1152/ ajpheart.1981.241.2.H202

Haverkamp, W., Breithardt, G., Camm, A. J., Janse, M. J., Rosen, M. R., Antzelevitch, C., et al. (2000). The potential for QT prolongation and proarrhythmia by non-anti-arrhythmic drugs: clinical and regulatory implications. Report on a Policy Conference of the European Society of Cardiology. Cardiovasc. Res. 47, 219-233. doi: 10.1016/S0008-6363(00)00119-X

Hinterseer, M., Thomsen, M. B., Beckmann, B. M., Pfeufer, A., Schimpf, R., Wichmann, H. E., et al. (2008). Beat-to-beat variability of QT intervals is increased in patients with drug-induced long-QT syndrome: a case control pilot study. Eur. Heart J. 29, 185-190. doi: 10.1093/eurheartj/ehm586

Hinterseer, M., Beckmann, B. M., Thomsen, M. B., Pfeufer, A., Dalla Pozza, R., Loeff, M., et al. (2009). Relation of increased short-term variability of QT interval to congenital long-QT syndrome. Am. J. Cardiol. 103, 1244-1248. doi: 10.1016/j.amjcard.2009.01.011

Hinterseer, M., Beckmann, B. M., Thomsen, M. B., Pfeufer, A., Ulbrich, M., Sinner, M. F., et al. (2010). Usefulness of short-term variability of QT intervals as a 
predictor for electrical remodeling and proarrhythmia in patients with nonischemic heart failure. Am. J. Cardiol. 106, 216-220. doi: 10.1016/ j.amjcard.2010.02.033

Hondeghem, L. M., and Hoffmann, P. (2003). Blinded test in isolated female rabbit heart reliably identifies action potential duration prolongation and proarrhythmic drugs: importance of triangulation, reverse use dependence, and instability. J. Cardiovasc. Pharmacol. 41, 14-24. doi: 10.1097/00005344200301000-00003

Hondeghem, L. M., Carlsson, L., and Duker, G. (2001). Instability and triangulation of the action potential predict serious proarrhythmia, but action potential duration prolongation is antiarrhythmic. Circulation 103, 2004-2013. doi: 10.1161/01.CIR.103.15.2004

Hondeghem, L. M., De Clerck, F., and Camm, J. (2007). Short patent lives jeopardize drug and patient safety. J. Cardiovasc. Pharmacol. 50, 353-357. doi: 10.1097/FJC.0b013e3181514032

Hondeghem, L. M. (2016). Disturbances of cardiac wavelength and repolarization precede Torsade de Pointes and ventricular fibrillation in Langendorff perfused rabbit hearts. Prog. Biophys. Mol. Biol. 121, 3-10. doi: 10.1016/ j.pbiomolbio.2016.03.004

Hornyik, T., Castiglione, A., Franke, G., Perez-Feliz, S., Major, P., Hiripi, L., et al. (2020). Transgenic LQT2, LQT5 and LQT2-5 rabbit models with decreased repolarization reserve for prediction of drug-induced ventricular arrhythmias. Br. J. Pharmacol. doi: 10.1111/bph.15098

Huang, H., Pugsley, M. K., Fermini, B., Curtis, M. J., Koerner, J., Accardi, M., et al. (2017). Cardiac voltage-gated ion channels in safety pharmacology: Review of the landscape leading to the CiPA initiative. J. Pharmacol. Toxicol. Methods 87, 11-23. doi: 10.1016/j.vascn.2017.04.002

Husti, Z., Tabori, K., Juhasz, V., Hornyik, T., Varro, A., and Baczko, I. (2015). Combined inhibition of key potassium currents has different effects on cardiac repolarization reserve and arrhythmia susceptibility in dogs and rabbits. Can. J. Physiol. Pharmacol. 93, 535-544. doi: 10.1139/cjpp-2014-0514

Inaba, H., Hayami, N., Ajiki, K., Kunishima, T., Watanabe, H., Tsutsui, K., et al. (2011). Deep anesthesia suppresses ventricular tachyarrhythmias in rabbit model of the acquired long QT syndrome. Circ. J. 75, 89-93. doi: 10.1253/ circj.CJ-10-0478

Jacobson, I., Carlsson, L., and Duker, G. (2011). Beat-by-beat QT interval variability, but not QT prolongation per se, predicts drug-induced torsades de pointes in the anaesthetised methoxamine-sensitized rabbit. J. Pharmacol. Toxicol. Methods 63, 40-46. doi: 10.1016/j.vascn.2010.04.010

Jameson, E., and Walter, J. (2008). Cardiac arrest secondary to long QT(C) in a child with propionic acidemia. Pediatr. Cardiol. 29, 969-970. doi: 10.1007/ s00246-007-9160-5

Jost, N., Virag, L., Bitay, M., Takacs, J., Lengyel, C., Biliczki, P., et al. (2005). Restricting excessive cardiac action potential and QT prolongation: a vital role for IKs in human ventricular muscle. Circulation 112, 1392-1399. doi: 10.1161/ CIRCULATIONAHA.105.550111

Jost, N., Virag, L., Comtois, P., Ordog, B., Szuts, V., Seprenyi, G., et al. (2013). Ionic mechanisms limiting cardiac repolarization reserve in humans compared to dogs. J. Physiol. 591, 4189-4206. doi: 10.1113/jphysiol.2013.261198

Jung, B., Odening, K. E., Dall'armellina, E., Foll, D., Menza, M., Markl, M., et al. (2012). A quantitative comparison of regional myocardial motion in mice, rabbits and humans using in-vivo phase contrast CMR. J. Cardiovasc. Magn. Reson 14, 87. doi: 10.1186/1532-429X-14-87

Kaab, S., Hinterseer, M., Nabauer, M., and Steinbeck, G. (2003). Sotalol testing unmasks altered repolarization in patients with suspected acquired long-QTsyndrome - a case-control pilot study using i.v. sotalol. Eur. Heart J. 24, 649657. doi: 10.1016/S0195-668X(02)00806-0

Kaese, S., and Verheule, S. (2012). Cardiac electrophysiology in mice: a matter of size. Front. Physiol. 3, 345. doi: 10.3389/fphys.2012.00345

Kakavand, B., Schroeder, V. A., and Di Sessa, T. G. (2006). Coincidence of long QT syndrome and propionic acidemia. Pediatr. Cardiol. 27, 160-161. doi: 10.1007/ s00246-005-1129-7

Kannankeril, P., Roden, D. M., and Darbar, D. (2010). Drug-induced long QT syndrome. Pharmacol. Rev. 62, 760-781. doi: 10.1124/pr.110.003723

Kim, T. Y., Kunitomo, Y., Pfeiffer, Z., Patel, D., Hwang, J., Harrison, K., et al. (2015). Complex excitation dynamics underlie polymorphic ventricular tachycardia in a transgenic rabbit model of long QT syndrome type 1. Heart Rhythm. 12, 220-228. doi: 10.1016/j.hrthm.2014.10.003
Kjekshus, J. (1990). Arrhythmias and mortality in congestive heart failure. Am. J. Cardiol. 65, 42I-48I. doi: 10.1016/0002-9149(90)90125-K

Kramer, J., Obejero-Paz, C. A., Myatt, G., Kuryshev, Y. A., Bruening-Wright, A., Verducci, J. S., et al. (2013). MICE models: superior to the HERG model in predicting Torsade de Pointes. Sci. Rep. 3, 2100. doi: 10.1038/srep02100

Kristof, A., Husti, Z., Koncz, I., Kohajda, Z., Szel, T., Juhasz, V., et al. (2012). Diclofenac prolongs repolarization in ventricular muscle with impaired repolarization reserve. PloS One 7, e53255. doi: 10.1371/journal.pone.0053255

Kurokawa, J., Tamagawa, M., Harada, N., Honda, S., Bai, C. X., Nakaya, H., et al. (2008). Acute effects of oestrogen on the guinea pig and human IKr channels and drug-induced prolongation of cardiac repolarization. J. Physiol. 586, $2961-$ 2973. doi: 10.1113/jphysiol.2007.150367

Kusano, K. F., Hata, Y., Yumoto, A., Emori, T., Sato, T., and Ohe, T. (2001). Torsade de pointes with a normal QT interval associated with hypokalemia: a case report. Jpn. Circ. J. 65, 757-760. doi: 10.1253/jci.65.757

Lang, C. N., Koren, G., and Odening, K. E. (2016). Transgenic rabbit models to investigate the cardiac ion channel disease long QT syndrome. Prog. Biophys. Mol. Biol. 121, 142-156. doi: 10.1016/j.pbiomolbio.2016.05.004

Lau, E., Kossidas, K., Kim, T. Y., Kunitomo, Y., Ziv, O., Song, Z., et al. (2015). Spatially Discordant Alternans and Arrhythmias in Tachypacing-Induced Cardiac Myopathy in Transgenic LQT1 Rabbits: The Importance of IKs and Ca2+ Cycling. PloS One 10, e0122754. doi: 10.1145/2818302

Lawrence, C. L., Pollard, C. E., Hammond, T. G., and Valentin, J. P. (2005). Nonclinical proarrhythmia models: predicting Torsades de Pointes. J. Pharmacol. Toxicol. Methods 52, 46-59. doi: 10.1016/j.vascn.2005.04.011

Lehmann, M. H., Hardy, S., Archibald, D., Quart, B., and Macneil, D. J. (1996). Sex difference in risk of torsade de pointes with d,l-sotalol. Circulation 94, 25352541. doi: 10.1161/01.CIR.94.10.2535

Lengyel, C., Varro, A., Tabori, K., Papp, J. G., and Baczko, I. (2007a). Combined pharmacological block of $\mathrm{I}(\mathrm{Kr})$ and $\mathrm{I}(\mathrm{Ks})$ increases short-term QT interval variability and provokes torsades de pointes. Br. J. Pharmacol. 151, 941-951. doi: 10.1038/sj.bjp.0707297

Lengyel, C., Virag, L., Biro, T., Jost, N., Magyar, J., Biliczki, P., et al. (2007b). Diabetes mellitus attenuates the repolarization reserve in mammalian heart. Cardiovasc. Res. 73, 512-520. doi: 10.1016/j.cardiores.2006.11.010

Lengyel, C., Virag, L., Kovacs, P. P., Kristof, A., Pacher, P., Kocsis, E., et al. (2008). Role of slow delayed rectifier $\mathrm{K}+$-current in QT prolongation in the alloxaninduced diabetic rabbit heart. Acta Physiol. (Oxf) 192, 359-368. doi: 10.1111/ j.1748-1716.2007.01753.x

Li, Z., Mirams, G. R., Yoshinaga, T., Ridder, B. J., Han, X., Chen, J. E., et al. (2019). General Principles for the Validation of Proarrhythmia Risk Prediction Models: An Extension of the CiPA In Silico Strategy. Clin. Pharmacol. Ther. 107, 102-111. doi: 10.1002/cpt.1647

Liu, X. K., Katchman, A., Whitfield, B. H., Wan, G., Janowski, E. M., Woosley, R. L., et al. (2003). In vivo androgen treatment shortens the QT interval and increases the densities of inward and delayed rectifier potassium currents in orchiectomized male rabbits. Cardiovasc. Res. 57, 28-36. doi: 10.1016/ S0008-6363(02)00673-9

Liu, G. X., Zhou, J., and Koren, G. (2008). Single-channel properties of I K,slow1 and I K,slow2 in mouse ventricular myocytes. Pflugers Arch. 456, 541-547. doi: 10.1007/s00424-007-0436-7

Liu, G. X., Choi, B. R., Ziv, O., Li, W., De Lange, E., Qu, Z., et al. (2012). Differential conditions for early after-depolarizations and triggered activity in cardiomyocytes derived from transgenic LQT1 and LQT2 rabbits. J. Physiol. 590, 1171-1180. doi: 10.1113/jphysiol.2011.218164

Liu, W., Kim, T. Y., Huang, X., Liu, M. B., Koren, G., Choi, B. R., et al. (2018). Mechanisms linking T-wave alternans to spontaneous initiation of ventricular arrhythmias in rabbit models of long QT syndrome. J. Physiol. 596, 1341-1355. doi: 10.1113/JP275492

Locati, E. H., Zareba, W., Moss, A. J., Schwartz, P. J., Vincent, G. M., Lehmann, M. H., et al. (1998). Age- and sex-related differences in clinical manifestations in patients with congenital long-QT syndrome: findings from the International LQTS Registry. Circulation 97, 2237-2244. doi: 10.1161/01.CIR.97.22.2237

London, B., Jeron, A., Zhou, J., Buckett, P., Han, X., Mitchell, G. F., et al. (1998). Long QT and ventricular arrhythmias in transgenic mice expressing the $\mathrm{N}$ terminus and first transmembrane segment of a voltage-gated potassium channel. Proc. Natl. Acad. Sci. U. S. A 95, 2926-2931. doi: 10.1073/ pnas.95.6.2926 
Major, P., Baczko, I., Hiripi, L., Odening, K. E., Juhasz, V., Kohajda, Z., et al. (2016). A novel transgenic rabbit model with reduced repolarization reserve: long QT syndrome caused by a dominant-negative mutation of the KCNE1 gene. Br. J. Pharmacol. 173, 2046-2061. doi: 10.1111/bph.13500

Malik, M. (2016). Drug-Induced QT/QTc Interval Shortening: Lessons from Drug-Induced QT/QTc Prolongation. Drug Saf. 39, 647-659. doi: 10.1007/ s40264-016-0411-3

Maron, B. J., Leyhe, M. J.3rd, Casey, S. A., Gohman, T. E., Lawler, C. M., Crow, R. S., et al. (2001). Assessment of QT dispersion as a prognostic marker for sudden death in a regional nonreferred hypertrophic cardiomyopathy cohort. Am. J. Cardiol. 87, 114-115, A119. doi: 10.1016/S0002-9149(00)01285-6

Maruyama, M., Lin, S. F., Xie, Y. F., Chua, S. K., Joung, B., Han, S., et al. (2011). Genesis of Phase 3 Early Afterdepolarizations and Triggered Activity in Acquired Long-QT Syndrome. Circulation-Arrhythmia Electrophysiol. 4, 103-10+. doi: 10.1161/CIRCEP.110.959064

Mcnally, P. G., Lawrence, I. G., Panerai, R. B., Weston, P. J., and Thurston, H. (1999). Sudden death in type 1 diabetes. Diabetes Obes. Metab. 1, 151-158. doi: 10.1046/j.1463-1326.1999.00025.x

Mehta, A., Chung, Y., Sequiera, G. L., Wong, P., Liew, R., and Shim, W. (2013). Pharmacoelectrophysiology of viral-free induced pluripotent stem cell-derived human cardiomyocytes. Toxicol. Sci. 131, 458-469. doi: 10.1093/toxsci/kfs309

Meijborg, V. M., Conrath, C. E., Opthof, T., Belterman, C. N., De Bakker, J. M., and Coronel, R. (2014). Electrocardiographic T wave and its relation with ventricular repolarization along major anatomical axes. Circ. Arrhythm. Electrophysiol. 7, 524-531. doi: 10.1161/CIRCEP.113.001622

Milberg, P., Frommeyer, G., Kleideiter, A., Fischer, A., Osada, N., Breithardt, G., et al. (2011). Antiarrhythmic effects of free polyunsaturated fatty acids in an experimental model of LQT2 and LQT3 due to suppression of early afterdepolarizations and reduction of spatial and temporal dispersion of repolarization. Heart Rhythm. 8, 1492-1500. doi: 10.1016/j.hrthm.2011.03.058

Monahan, B. P., Ferguson, C. L., Killeavy, E. S., Lloyd, B. K., Troy, J., and Cantilena, L. R.Jr. (1990). Torsades de pointes occurring in association with terfenadine use. JAMA 264, 2788-2790. doi: 10.1001/ jama.1990.03450210088038

Moshal, K. S., Zhang, Z., Roder, K., Kim, T. Y., Cooper, L., Patedakis Litvinov, B., et al. (2014). Progesterone modulates SERCA2a expression and function in rabbit cardiomyocytes. Am. J. Physiol. Cell Physiol. 307, C1050-C1057. doi: 10.1152/ajpcell.00127.2014

Mow, T., Frederiksen, K., and Thomsen, M. B. (2015). Assessment of antiarrhythmic activity of antipsychotic drugs in an animal model: influence of non-cardiac alpha(1)-adrenergic receptors. Eur. J. Pharmacol. 748, 10-17. doi: 10.1016/j.ejphar.2014.12.012

Nagy, N., Szuts, V., Horvath, Z., Seprenyi, G., Farkas, A. S., Acsai, K., et al. (2009). Does small-conductance calcium-activated potassium channel contribute to cardiac repolarization? J. Mol. Cell Cardiol. 47, 656-663. doi: 10.1016/ j.yjmcc.2009.07.019

Nerbonne, J. M., and Kass, R. S. (2005). Molecular physiology of cardiac repolarization. Physiol. Rev. 85, 1205-1253. doi: 10.1152/physrev.00002.2005

Nerbonne, J. M., Nichols, C. G., Schwarz, T. L., and Escande, D. (2001). Genetic manipulation of cardiac $\mathrm{K}(+)$ channel function in mice: what have we learned, and where do we go from here? Circ. Res. 89, 944-956. doi: 10.1161/ hh2301.100349

Nerbonne, J. M. (2000). Molecular basis of functional voltage-gated K+ channel diversity in the mammalian myocardium. J. Physiol. 525 Pt 2, 285-298. doi: 10.1111/j.1469-7793.2000.t01-1-00285.x

Nuyens, D., Stengl, M., Dugarmaa, S., Rossenbacker, T., Compernolle, V., Rudy, Y., et al. (2001). Abrupt rate accelerations or premature beats cause lifethreatening arrhythmias in mice with long-QT3 syndrome. Nat. Med. 7, 10211027. doi: 10.1038/nm0901-1021

Odening, K. E., and Koren, G. (2014). How do sex hormones modify arrhythmogenesis in long QT syndrome? Sex hormone effects on arrhythmogenic substrate and triggered activity. Heart Rhythm. 11, 21072115. doi: 10.1016/j.hrthm.2014.06.023

Odening, K. E., Hyder, O., Chaves, L., Schofield, L., Brunner, M., Kirk, M., et al. (2008). Pharmacogenomics of anesthetic drugs in transgenic LQT1 and LQT2 rabbits reveal genotype-specific differential effects on cardiac repolarization. Am. J. Physiol. Heart Circ. Physiol. 295, H2264-H2272. doi: 10.1152/ ajpheart.00680.2008
Odening, K. E., Kirk, M., Brunner, M., Ziv, O., Lorvidhaya, P., Liu, G. X., et al. (2010). Electrophysiological studies of transgenic long QT type 1 and type 2 rabbits reveal genotype-specific differences in ventricular refractoriness and His conduction. Am. J. Physiol. Heart Circ. Physiol. 299, H643-H655. doi: 10.1152/ajpheart.00074.2010

Odening, K. E., Choi, B. R., and Koren, G. (2012a). Sex hormones and cardiac arrest in long QT syndrome: does progesterone represent a potential new antiarrhythmic therapy? Heart Rhythm. 9, 1150-1152. doi: 10.1016/ j.hrthm.2012.02.028

Odening, K. E., Choi, B. R., Liu, G. X., Hartmann, K., Ziv, O., Chaves, L., et al. (2012b). Estradiol promotes sudden cardiac death in transgenic long QT type 2 rabbits while progesterone is protective. Heart Rhythm. 9, 823-832. doi: 10.1016/j.hrthm.2012.01.009

Odening, K. E., Jung, B. A., Lang, C. N., Cabrera Lozoya, R., Ziupa, D., Menza, M., et al. (2013). Spatial correlation of action potential duration and diastolic dysfunction in transgenic and drug-induced LQT2 rabbits. Heart Rhythm. 10, 1533-1541. doi: 10.1016/j.hrthm.2013.07.038

Odening, K. E., Bodi, I., Franke, G., Rieke, R., Ryan De Medeiros, A., Perez-Feliz, S., et al. (2019). Transgenic short-QT syndrome 1 rabbits mimic the human disease phenotype with QT/action potential duration shortening in the atria and ventricles and increased ventricular tachycardia/ventricular fibrillation inducibility. Eur. Heart J. 40, 842-853. doi: 10.1093/eurheartj/ehy761

Oosterhoff, P., Thomsen, M. B., Maas, J. N., Atteveld, N. J., Beekman, J. D., HV, V. A. N. R., et al. (2010). High-rate pacing reduces variability of repolarization and prevents repolarization-dependent arrhythmias in dogs with chronic AV block. J. Cardiovasc. Electrophysiol. 21, 1384-1391. doi: 10.1111/j.1540-8167.2010.01824.x

Oros, A., Volders, P. G., Beekman, J. D., Van Der Nagel, T., and Vos, M. A. (2006). Atrial-specific drug AVE0118 is free of torsades de pointes in anesthetized dogs with chronic complete atrioventricular block. Heart Rhythm. 3, 1339-1345. doi: 10.1016/j.hrthm.2006.07.017

Orosz, S., Sarusi, A., Csik, N., Papp, J. G., Varro, A., Farkas, S., et al. (2014). Assessment of efficacy of proarrhythmia biomarkers in isolated rabbit hearts with attenuated repolarization reserve. J. Cardiovasc. Pharmacol. 64, 266-276. doi: 10.1097/FJC.0000000000000116

Orosz, A., Baczko, I., Nagy, V., Gavaller, H., Csanady, M., Forster, T., et al. (2015a). Short-term beat-to-beat variability of the QT interval is increased and correlates with parameters of left ventricular hypertrophy in patients with hypertrophic cardiomyopathy. Can. J. Physiol. Pharmacol. 93, 765-772. doi: 10.1139/cjpp-2014-0526

Orosz, A., Csajbok, E., Czekus, C., Gavaller, H., Magony, S., Valkusz, Z., et al. (2015b). Increased Short-Term Beat-To-Beat Variability of QT Interval in Patients with Acromegaly. PloS One 10, e0125639. doi: 10.1371/ journal.pone.0125639

Orosz, A., Baczko, I., Nyiraty, S., Korei, A. E., Putz, Z., Takacs, R., et al. (2017). Increased Short-Term Beat-to-Beat QT Interval Variability in Patients with Impaired Glucose Tolerance. Front. Endocrinol. (Lausanne) 8, 129. doi: 10.3389/fendo.2017.00129

Ortega, F. A., Grandi, E., Krogh-Madsen, T., and Christini, D. J. (2017). Applications of Dynamic Clamp to Cardiac Arrhythmia Research: Role in Drug Target Discovery and Safety Pharmacology Testing. Front. Physiol. 8, 1099. doi: 10.3389/fphys.2017.01099

Paltoo, B., O'donoghue, S., and Mousavi, M. S. (2001). Levofloxacin induced polymorphic ventricular tachycardia with normal QT interval. Pacing Clin. Electrophysiol. 24, 895-897. doi: 10.1046/j.1460-9592.2001.00895.x

Panfilov, A. V. (2006). Is heart size a factor in ventricular fibrillation? Or how close are rabbit and human hearts? Heart Rhythm. 3, 862-864.

Parikh, A., Mantravadi, R., Kozhevnikov, D., Roche, M. A., Ye, Y. P., Owen, L. J et al. (2012). Ranolazine stabilizes cardiac ryanodine receptors: A novel mechanism for the suppression of early afterdepolarization and torsades de pointes in long QT type 2. Heart Rhythm. 9, 953-960. doi: 10.1016/ j.hrthm.2012.01.010

Park, E., Gintant, G. A., Bi, D., Kozeli, D., Pettit, S. D., Pierson, J. B., et al. (2018). Can non-clinical repolarization assays predict the results of clinical thorough QT studies? Results from a research consortium. Br. J. Pharmacol. 175, 606617. doi: 10.1111/bph.14101

Patel, S. P., and Campbell, D. L. (2005). Transient outward potassium current, 'Ito', phenotypes in the mammalian left ventricle: underlying molecular, 
cellular and biophysical mechanisms. J. Physiol. 569, 7-39. doi: 10.1113/ jphysiol.2005.086223

Pollard, C. E., Abi Gerges, N., Bridgland-Taylor, M. H., Easter, A., Hammond, T. G., and Valentin, J. P. (2010). An introduction to QT interval prolongation and nonclinical approaches to assessing and reducing risk. Br. J. Pharmacol. 159, 12-21. doi: 10.1111/j.1476-5381.2009.00207.x

Pugsley, M. K., Authier, S., and Curtis, M. J. (2008). Principles of safety pharmacology. Br. J. Pharmacol. 154, 1382-1399. doi: 10.1038/bjp.2008.280

Redfern, W. S., Carlsson, L., Davis, A. S., Lynch, W. G., Mackenzie, I., Palethorpe, S., et al. (2003). Relationships between preclinical cardiac electrophysiology, clinical QT interval prolongation and torsade de pointes for a broad range of drugs: evidence for a provisional safety margin in drug development. Cardiovasc. Res. 58, 32-45. doi: 10.1016/S0008-6363(02)00846-5

Roden, D. M. (1998). Taking the "idio" out of "idiosyncratic": predicting torsades de pointes. Pacing Clin. Electrophysiol. 21, 1029-1034. doi: 10.1111/j.15408159.1998.tb00148.x

Roden, D. M. (2004). Drug-induced prolongation of the QT interval. N. Engl. J. Med. 350, 1013-1022. doi: 10.1056/NEJMra032426

Roden, D. M. (2008). Cellular basis of drug-induced torsades de pointes. Br. J. Pharmacol. 154, 1502-1507. doi: 10.1038/bjp.2008.238

Rodriguez, I., Kilborn, M. J., Liu, X. K., Pezzullo, J. C., and Woosley, R. L. (2001). Drug-induced QT prolongation in women during the menstrual cycle. JamaJournal Am. Med. Assoc. 285, 1322-1326. doi: 10.1001/jama.285.10.1322

Rudy, Y., Ackerman, M. J., Bers, D. M., Clancy, C. E., Houser, S. R., London, B., et al. (2008). Systems approach to understanding electromechanical activity in the human heart: a national heart, lung, and blood institute workshop summary. Circulation 118, 1202-1211. doi: 10.1161/CIRCULATIONAHA.108.772715

Sager, P. T., Gintant, G., Turner, J. R., Pettit, S., and Stockbridge, N. (2014). Rechanneling the cardiac proarrhythmia safety paradigm: a meeting report from the Cardiac Safety Research Consortium. Am. Heart J. 167, 292-300. doi: 10.1016/j.ahj.2013.11.004

Saito, T., Ciobotaru, A., Bopassa, J. C., Toro, L., Stefani, E., and Eghbali, M. (2009). Estrogen contributes to gender differences in mouse ventricular repolarization. Circ. Res. 105, 343-352. doi: 10.1161/CIRCRESAHA.108.190041

Salama, G., and London, B. (2007). Mouse models of long QT syndrome. J. Physiol. 578, 43-53. doi: 10.1113/jphysiol.2006.118745

Sauer, A. J., Moss, A. J., Mcnitt, S., Peterson, D. R., Zareba, W., Robinson, J. L., et al. (2007). Long QT syndrome in adults. J. Am. Coll. Cardiol. 49, 329-337. doi: $10.1016 /$ j.jacc.2006.08.057

Selzer, A., and Wray, H. W. (1964). Quinidine Syncope. Paroxysmal Ventricular Fibrillation Occurring during Treatment of Chronic Atrial Arrhythmias. Circulation 30, 17-26. doi: 10.1161/01.CIR.30.1.17

Seth, R., Moss, A. J., Mcnitt, S., Zareba, W., Andrews, M. L., Qi, M., et al. (2007). Long QT syndrome and pregnancy. J. Am. Coll. Cardiol. 49, 1092-1098. doi: 10.1016/j.jacc.2006.09.054

Shah, R. R., and Hondeghem, L. M. (2005). Refining detection of drug-induced proarrhythmia: QT interval and TRIaD. Heart Rhythm. 2, 758-772. doi: 10.1016/j.hrthm.2005.03.023

Stansfeld, P. J., Sutcliffe, M. J., and Mitcheson, J. S. (2006). Molecular mechanisms for drug interactions with hERG that cause long QT syndrome. Expert Opin. Drug Metab. Toxicol. 2, 81-94. doi: 10.1517/17425255.2.1.81

Stockbridge, N., Morganroth, J., Shah, R. R., and Garnett, C. (2013). Dealing with global safety issues : was the response to QT-liability of non-cardiac drugs well coordinated? Drug Saf. 36, 167-182. doi: 10.1007/s40264-013-0016-z

Strasberg, B., Welch, W., Palileo, E., Swiryn, S., Bauernfeind, R., and Rosen, K. M. (1983). Familial inducible torsade de pointes with normal QT interval. Eur. Heart J. 4, 383-390. doi: 10.1093/oxfordjournals.eurheartj.a061484

Sugiyama, A., Satoh, Y., Shiina, H., Takeda, S., and Hashimoto, K. (2002). Torsadegenic action of the antipsychotic drug sulpiride assessed using in vivo canine models. J. Cardiovasc. Pharmacol. 40, 235-245. doi: 10.1097/ 00005344-200208000-00009

Takahara, A., Sugiyama, A., Ishida, Y., Satoh, Y., Wang, K., Nakamura, Y., et al. (2006). Long-term bradycardia caused by atrioventricular block can remodel the canine heart to detect the histamine $\mathrm{H} 1$ blocker terfenadine-induced torsades de pointes arrhythmias. Br. J. Pharmacol. 147, 634-641. doi: 10.1038/sj.bjp.0706493

Thomsen, M. B., Volders, P. G., Stengl, M., Spatjens, R. L., Beekman, J. D., Bischoff, U., et al. (2003). Electrophysiological safety of sertindole in dogs with normal and remodeled hearts. J. Pharmacol. Exp. Ther. 307, 776-784. doi: 10.1124/jpet.103.052753

Thomsen, M. B., Verduyn, S. C., Stengl, M., Beekman, J. D., De Pater, G., Van Opstal, J., et al. (2004). Increased short-term variability of repolarization predicts d-sotalol-induced torsades de pointes in dogs. Circulation 110, 2453-2459. doi: 10.1161/01.CIR.0000145162.64183.C8

Thomsen, M. B., Beekman, J. D., Attevelt, N. J., Takahara, A., Sugiyama, A., Chiba, K., et al. (2006a). No proarrhythmic properties of the antibiotics Moxifloxacin or Azithromycin in anaesthetized dogs with chronic-AV block. $\mathrm{Br} . \mathrm{J}$. Pharmacol. 149, 1039-1048. doi: 10.1038/sj.bjp.0706900

Thomsen, M. B., Volders, P. G., Beekman, J. D., Matz, J., and Vos, M. A. (2006b). Beat-to-Beat variability of repolarization determines proarrhythmic outcome in dogs susceptible to drug-induced torsades de pointes. J. Am. Coll. Cardiol. 48, 1268-1276. doi: 10.1016/j.jacc.2006.05.048

Van Opstal, J. M., Schoenmakers, M., Verduyn, S. C., De Groot, S. H., Leunissen, J. D., Van Der Hulst, F. F., et al. (2001). Chronic amiodarone evokes no torsade de pointes arrhythmias despite QT lengthening in an animal model of acquired longQT syndrome. Circulation 104, 2722-2727. doi: 10.1161/hc4701.099579

Varkevisser, R., Wijers, S. C., Van Der Heyden, M. A., Beekman, J. D., Meine, M., and Vos, M. A. (2012). Beat-to-beat variability of repolarization as a new biomarker for proarrhythmia in vivo. Heart Rhythm. 9, 1718-1726. doi: 10.1016/j.hrthm.2012.05.016

Varkevisser, R., Vos, M. A., Beekman, J. D., Tieland, R. G., and Van Der Heyden, M. A. (2015). AV-block and conduction slowing prevail over TdP arrhythmias in the methoxamine-sensitized pro-arrhythmic rabbit model. J. Cardiovasc. Electrophysiol. 26, 82-89. doi: 10.1111/jce.12533

Varro, A., and Baczko, I. (2011). Cardiac ventricular repolarization reserve: a principle for understanding drug-related proarrhythmic risk. Br. J. Pharmacol. 164, 14-36. doi: 10.1111/j.1476-5381.2011.01367.x

Varro, A., Lathrop, D. A., Hester, S. B., Nanasi, P. P., and Papp, J. G. (1993). Ionic currents and action potentials in rabbit, rat, and guinea pig ventricular myocytes. Basic Res. Cardiol. 88, 93-102. doi: 10.1007/BF00798257

Varro, A., Balati, B., Iost, N., Takacs, J., Virag, L., Lathrop, D. A., et al. (2000). The role of the delayed rectifier component IKs in dog ventricular muscle and Purkinje fibre repolarization. J. Physiol. 523 Pt 1, 67-81. doi: 10.1111/j.1469-7793.2000.00067.x

Verduyn, S. C., Van Opstal, J. M., Leunissen, J. D., and Vos, M. A. (2001). Assessment of the pro-arrhythmic potential of anti-arrhythmic drugs: an experimental approach. J. Cardiovasc. Pharmacol. Ther. 6, 89-97. doi: 10.1177/107424840100600109

Volders, P. G., Sipido, K. R., Vos, M. A., Spatjens, R. L., Leunissen, J. D., Carmeliet, E., et al. (1999). Downregulation of delayed rectifier $\mathrm{K}(+)$ currents in dogs with chronic complete atrioventricular block and acquired torsades de pointes. Circulation 100, 2455-2461. doi: 10.1161/01.CIR.100.24.2455

Volders, P. G., Stengl, M., Van Opstal, J. M., Gerlach, U., Spatjens, R. L., Beekman, J. D., et al. (2003). Probing the contribution of IKs to canine ventricular repolarization: key role for beta-adrenergic receptor stimulation. Circulation 107, 2753-2760. doi: 10.1161/01.CIR.0000068344.54010.B3

Vos, M. A., Verduyn, S. C., Gorgels, A. P., Lipcsei, G. C., and Wellens, H. J. (1995). Reproducible induction of early afterdepolarizations and torsade de pointes arrhythmias by $\mathrm{d}$-sotalol and pacing in dogs with chronic atrioventricular block. Circulation 91, 864-872. doi: 10.1161/01.CIR.91.3.864

Vos, M. A., De Groot, S. H., Verduyn, S. C., Van Der Zande, J., Leunissen, H. D., Cleutjens, J. P., et al. (1998). Enhanced susceptibility for acquired torsade de pointes arrhythmias in the dog with chronic, complete AV block is related to cardiac hypertrophy and electrical remodeling. Circulation 98, 1125-1135. doi: 10.1161/01.CIR.98.11.1125

Waldo, A. L., Camm, A. J., Deruyter, H., Friedman, P. L., Macneil, D. J., Pauls, J. F., et al. (1996). Effect of d-sotalol on mortality in patients with left ventricular dysfunction after recent and remote myocardial infarction. The SWORD Investigators. Survival With Oral d-Sotalol. Lancet 348, 7-12. doi: 10.1016/ S0140-6736(96)02149-6

Whitsel, E. A., Boyko, E. J., Rautaharju, P. M., Raghunathan, T. E., Lin, D., Pearce, R. M., et al. (2005). Electrocardiographic QT interval prolongation and risk of primary cardiac arrest in diabetic patients. Diabetes Care 28, 2045-2047. doi: 10.2337/diacare.28.8.2045

Wolbrette, D. L. (2003). Risk of proarrhythmia with class III antiarrhythmic agents: sex-based differences and other issues. Am. J. Cardiol. 91, 39D-44D. doi: 10.1016/S0002-9149(02)03378-7 
Woosley, R. L., Chen, Y., Freiman, J. P., and Gillis, R. A. (1993). Mechanism of the cardiotoxic actions of terfenadine. JAMA 269, 1532-1536. doi: 10.1001/ jama.1993.03500120070028

Wysowski, D. K., and Bacsanyi, J. (1996). Cisapride and fatal arrhythmia. N. Engl. J. Med. 335, 290-291. doi: 10.1056/NEJM199607253350416

Xu, H., Guo, W., and Nerbonne, J. M. (1999). Four kinetically distinct depolarization-activated $\mathrm{K}+$ currents in adult mouse ventricular myocytes. J. Gen. Physiol. 113, 661-678. doi: 10.1085/jgp.113.5.661

Yang, P. C., and Clancy, C. E. (2010). Effects of sex hormones on cardiac repolarization. J. Cardiovasc. Pharmacol. 56, 123-129. doi: 10.1097/ FJC.0b013e3181d6f7dd

Yang, P. C., and Clancy, C. E. (2011). Gender-based differences in cardiac diseases. J. BioMed. Res. 25, 81-89. doi: 10.1016/S1674-8301(11)60010-9

Yang, T., Snyders, D., and Roden, D. M. (2001). Drug block of I(kr): model systems and relevance to human arrhythmias. J. Cardiovasc. Pharmacol. 38, 737-744. doi: 10.1097/00005344-200111000-00010

Yang, T., Chun, Y. W., Stroud, D. M., Mosley, J. D., Knollmann, B. C., Hong, C., et al. (2014). Screening for acute IKr block is insufficient to detect torsades de pointes liability: role of late sodium current. Circulation 130, 224-234. doi: 10.1161/CIRCULATIONAHA.113.007765

Yang, P. C., El-Bizri, N., Romero, L., Giles, W. R., Rajamani, S., Belardinelli, L., et al. (2016). A computational model predicts adjunctive pharmacotherapy for cardiac safety via selective inhibition of the late cardiac Na current. J. Mol. Cell Cardiol. 99, 151-161. doi: 10.1016/j.yjmcc.2016.08.011

Yap, Y. G., and Camm, A. J. (2003). Drug induced QT prolongation and torsades de pointes. Heart 89, 1363-1372. doi: 10.1136/heart.89.11.1363

Yi, G., Elliott, P., Mckenna, W. J., Prasad, K., Sharma, S., Guo, X. H., et al. (1998). QT dispersion and risk factors for sudden cardiac death in patients with hypertrophic cardiomyopathy. Am. J. Cardiol. 82, 1514-1519. doi: 10.1016/ S0002-9149(98)00696-1

Zhang, S., Zhou, Z., Gong, Q., Makielski, J. C., and January, C. T. (1999). Mechanism of block and identification of the verapamil binding domain to HERG potassium channels. Circ. Res. 84, 989-998. doi: 10.1161/01.RES.84.9.989

Ziupa, D., Beck, J., Franke, G., Perez Feliz, S., Hartmann, M., Koren, G., et al. (2014). Pronounced effects of HERG-blockers E-4031 and erythromycin on APD, spatial APD dispersion and triangulation in transgenic long-QT type 1 rabbits. PloS One 9, e107210. doi: 10.1371/journal.pone.0107210

Ziupa, D., Menza, M., Koppermann, S., Moss, R., Beck, J., Franke, G., et al. (2019). Electro-mechanical (dys-)function in long QT syndrome type 1. Int. J. Cardiol. 274, 144-151. doi: 10.1016/j.ijcard.2018.07.050

Ziv, O., Morales, E., Song, Y. K., Peng, X., Odening, K. E., Buxton, A. E., et al. (2009). Origin of complex behaviour of spatially discordant alternans in a transgenic rabbit model of type 2 long QT syndrome. J. Physiol. 587, 46614680. doi: 10.1113/jphysiol.2009.175018

Conflict of Interest: The authors declare that the research was conducted in the absence of any commercial or financial relationships that could be construed as a potential conflict of interest.

Copyright (c) 2020 Baczkó, Hornyik, Brunner, Koren and Odening. This is an openaccess article distributed under the terms of the Creative Commons Attribution License (CC BY). The use, distribution or reproduction in other forums is permitted, provided the original author(s) and the copyright owner(s) are credited and that the original publication in this journal is cited, in accordance with accepted academic practice. No use, distribution or reproduction is permitted which does not comply with these terms. 